\title{
ISPD GUIDELINES/RECOMMENDATIONS
}

\section{ISPD PERITONITIS RECOMMENDATIONS: 2016 UPDATE ON PREVENTION AND TREATMENT}

\author{
Philip Kam-Tao Li, ${ }^{1}$ Cheuk Chun Szeto, ${ }^{1}$ Beth Piraino, ${ }^{2}$ Javier de Arteaga, ${ }^{3}$ Stanley Fan, ${ }^{4}$ Ana E. Figueiredo, ${ }^{5}$ \\ Douglas N. Fish, ${ }^{6}$ Eric Goffin, ${ }^{7}$ Yong-Lim Kim, ${ }^{8}$ William Salzer, ${ }^{9}$ Dirk G. Struijk, ${ }^{10}$ \\ Isaac Teitelbaum, ${ }^{11}$ and David W. Johnson ${ }^{12}$
}

Department of Medicine and Therapeutics, ${ }_{1}$ Prince of Wales Hospital, The Chinese University of Hong Kong, Hong Kong; University of Pittsburgh School of Medicine, ${ }^{2}$ Pittsburgh, PA, USA; Department of Nephrology, ${ }^{3}$ Hospital Privado and Catholic University, Cordoba, Argentina; Department of Renal Medicine and Transplantation, ${ }^{4}$ Barts Health NHS Trust, London, UK; Nursing School-FAENFI, ${ }^{5}$ Pontificia Universidade Catolica do Rio Grande do Sul, Porto Alegre, Brazil; Department of Clinical Pharmacy, ${ }^{6}$ Skaggs School of Pharmacy and Pharmaceutical Sciences, University of Colorado, Aurora, CO, USA; Department of Nephrology, ${ }^{7}$ Cliniques Universitaires Saint-Luc, Université catholique de Louvain, Belgium; Department of Internal Medicine, ${ }^{8}$ Kyungpook National University School of Medicine,

Clinical Research Center for End Stage Renal Disease, Daegu, Korea; University of Missouri-Columbia School of Medicine, ${ }^{9}$ Department of Internal Medicine, Section of Infectious Disease, MI, USA;

Department of Nephrology, ${ }_{1}^{10}$ Academic Medical Center, University of Amsterdam, Amsterdam,

The Netherlands; University of Colorado Hospital, ${ }^{11}$ Aurora, CO, USA; and

Department of Nephrology, ${ }_{12}^{12}$ University of Queensland at

Princess Alexandra Hospital, Brisbane, Australia ISPD.

KEY WORDS: Peritonitis; guidelines; prevention; treatment;

P eritonitis is a common and serious complication of peritoneal dialysis (PD). Although less than $5 \%$ of peritonitis episodes result in death, peritonitis is the direct or major contributing cause of death in around $16 \%$ of PD patients (1-6). In addition, severe or prolonged peritonitis leads to structural and functional alterations of the peritoneal membrane, eventually leading to membrane failure. Peritonitis is a major cause of PD technique failure and conversion to longterm hemodialysis $(1,5,7,8)$.

Recommendations under the auspices of the International Society for Peritoneal Dialysis (ISPD) were first published in 1983 and revised in 1993, 1996, 2000, 2005, and 2010 (9-14). The present recommendations are organized into 5 sections:

\section{Peritonitis rate}

Correspondence to: Philip Kam-Tao Li, CUHK Carol \& Richard Yu PD Research Centre, Department of Medicine and Therapeutics, Prince of Wales Hospital, The Chinese University of Hong Kong, Hong Kong. philipli@cuhk.edu.hk Received 20 March 2016; accepted 4 May 2016.
2. Prevention of peritonitis

3. Initial presentation and management of peritonitis

4. Subsequent management of peritonitis

5. Future research

These recommendations are evidence-based where such evidence exists. Publications in or before December 2015 were reviewed. The bibliography is not intended to be comprehensive. When there were many similar publications on the same area, the committee included articles that were recently published. In general, these recommendations follow the Grades of Recommendation Assessment, Development and Evaluation (GRADE) system for classification of the level of evidence and grade of recommendations in clinical guideline reports (15). Within each recommendation, the strength of the recommendation is indicated as Level 1 (We recommend), Level 2 (We suggest), or not graded, and the quality of the supporting evidence is shown as A (high quality), B (moderate quality), C (low quality), or D (very low quality). The recommendations are not meant to be implemented in every

Perit Dial Int 2016; 36(5):481-508 epub ahead of print: 09 June 2016 http://dx.doi.org/10.3747/pdi.2016.00078

This single copy is for your personal, non-commercial use only.

For permission to reprint multiple copies or to order presentation-ready

copies for distribution, contact Multimed Inc. at marketing@multi-med.com 
situation indiscriminately. Each PD unit should examine its own pattern of infection, causative organisms, and sensitivities, and adapt the protocols according to local conditions as necessary. Although many of the general principles presented here could be applied to pediatric patients, we focus on peritonitis in adult patients. Clinicians who take care of pediatric PD patients should refer to the latest consensus guideline from our pediatric colleagues for detailed treatment regimens and dosages (16).

\section{PERITONITIS RATE}

- We recommend that every program should monitor, at least on a yearly basis, the incidence of peritonitis (1C).

- We recommend that the parameters monitored should include the overall peritonitis rate, peritonitis rates of specific organisms, the percentage of patients per year who are peritonitis-free, and the antimicrobial susceptibilities of the infecting organisms (1C).

- We suggest that peritonitis rate should be standardly reported as number of episodes per patient-year (not graded).

- We suggest that organism-specific peritonitis rates should be reported as absolute rates, i.e. as number of episodes per year (not graded).

As part of a continuous quality improvement (CQI) program, all PD programs should monitor the incidence of peritonitis on a regular basis (17-19). During the computation, only peritonitis episodes that developed from the first day of PD training should be counted, while relapsing episodes should only be counted once. However, it may also be useful to monitor any peritonitis episode that develops after catheter insertion and before PD training is started. Peritonitis episodes that develop while the patient is hospitalized and PD performed by nurses should also be counted. In addition to the overall peritonitis rate, monitoring should include the peritonitis rate of specific organisms and drug susceptibilities of the infecting organisms (20), which may help to design centerspecific empirical antibiotic regimens. With this information, interventions can be implemented when peritonitis rates are rising or unacceptably high.

There is a substantial variation in the peritonitis rate reported by different countries, as well as a great deal of variation within countries that is not well explained $(1,3,14,19,21-26)$. Nonetheless, the overall peritonitis rate should be no more than 0.5 episodes per year at risk, although the rate achieved depends considerably on the patient population. In some outstanding centers, an overall peritonitis rate as low as 0.18 to 0.20 episode per year has been reported $(27,28)$. All centers should work to continuously improve their peritonitis rates. There are several methods of reporting peritonitis rates (Table 1) $(13,29)$, and expressing as number of patient-month per episode has been commonly used. However, the committee favors reporting peritonitis rates as number of episodes per year as data are presented
TABLE 1

Methods for Reporting Peritonitis

- As rates (calculated for all infections and each organism): Number of infections by organism for a time period, divided by dialysisyears' time at risk, and expressed as episodes per year.

- As percentage of patients per period of time who are peritonitis free.

- As median peritonitis rate for the program (calculate peritonitis rate for each patient, and then obtain the median of these rates).

N.B. Relapsing peritonitis (see Table 6 for the definition) should be counted as a single episode.

in a linear scale. Some centers also monitor the incidence of death associated with peritonitis, which is typically defined as death with active peritonitis or within 4 weeks of a peritonitis episode, or any death during hospitalization for a peritonitis episode $(6,12,30)$.

\section{PREVENTION OF PERITONITIS}

Exit-site and catheter-tunnel infections are major predisposing factors to PD-related peritonitis (31). Many prevention strategies aim to reduce the incidence of exit-site and cathetertunnel infections, and clinical trials in this area often report peritonitis rates as a secondary outcome. In this guideline, we focus on the prevention of peritonitis. The prevention of exit-site and catheter-tunnel infections will be covered in a separate guideline.

\section{CATHETER PLACEMENT}

- We recommend that systemic prophylactic antibiotics be administered immediately prior to catheter insertion (1A).

Detailed description of the recommended practice of PD catheter insertion has been covered in another ISPD position paper (32). There are 4 randomized, controlled trials on the use of perioperative intravenous (IV) cefuroxime (33), gentamicin $(34,35)$, vancomycin $(36)$, and cefazolin $(35,36)$ as compared to no treatment. Three of them showed that perioperative antibiotic reduces the incidence of early peritonitis (34-36), while 1 that used cefazolin and gentamicin found no benefit (35). Vancomycin and cefazolin were compared head-to-head in 1 study (36), which showed that vancomycin is more effective than cefazolin. The overall benefit of prophylactic perioperative IV antibiotics was confirmed by a systematic review of these 4 trials (37). Although first-generation cephalosporin may be slightly less effective than vancomycin, the former is still commonly used because of the concern regarding vancomycin resistance. Each PD program should determine its own choice of antibiotic for prophylaxis after considering the local spectrum of antibiotic resistance. No data exist on the effectiveness of routine screening and eradication of Staphylococcus aureus nasal carriage before catheter insertion (e.g. by intranasal mupirocin). 
Besides prophylactic antibiotics, various techniques of catheter placement have been tested. Four randomized trials have compared laparoscopic or peritoneoscopic catheter placement with standard laparotomy (38-41). One study showed that peritoneoscopic insertion led to significantly less early peritonitis (38), but the other 3 were negative (39-41). A systematic review concluded that there is no significant difference in peritonitis rate between these techniques (42). Two studies compared midline with lateral incision $(43,44)$, but neither found any difference in peritonitis rate. Several studies examined the technique of burying the PD catheter in subcutaneous tissue for 4 to 6 weeks after implantation (45-47). The first prospective study with historic control found a decrease in rate of peritonitis (45). In the 2 subsequent randomized studies, one showed a decrease in peritonitis rate with a buried catheter (46), while the other showed no difference (47). One retrospective study found no difference in peritonitis rate between pre-sternal and abdominal swan-neck catheters (48). In summary, there are no convincing data that the buried catheter technique lowers peritonitis rates.

\section{CATHETER DESIGN}

- The committee has no specific recommendation on catheter design for prevention of peritonitis.

There are no convincing data regarding the effect of PD catheter design and configuration on peritonitis risk. Eight randomized trials have compared straight and coiled PD catheters (49-55) and found no difference in peritonitis rate. Two systemic reviews of these trials had the same conclusion $(42,56)$. Two randomized controlled trials found no difference in peritonitis rate between a swan-neck design and the traditional Tenckhoff catheter $(57,58)$. Several retrospective studies suggested that double-cuffed catheters are associated with a lower peritonitis rate than single-cuffed ones (59-62). However, the only randomized trial on this topic showed no difference in peritonitis risk between the two catheter types (63). Downward direction of the tunnel and exit site has theoretical benefits and is often advocated for the prevention of catheterrelated peritonitis, but the data supporting this are weak (64).

\section{CONNECTION METHODS}

- We recommend that disconnect systems with a "flush before fill" design be used for continuous ambulatory PD (CAPD) (1A).

For CAPD, several prospective studies confirm that the use of Y connection systems with the "flush before fill" design results in a lower peritonitis rate than the traditional spike systems $(65-80)$. Two systematic reviews concluded that the risk of developing peritonitis was reduced by about one-third with the use of $Y$ systems $(42,81)$. Among all disconnect systems, 1 previous systematic review showed a significantly lower risk of peritonitis with double bag compared with the standard $Y$ systems (82). On the other hand, 2 updated systematic reviews did not find any difference $(42,81)$. It was suggested that the use of conservative statistical techniques might have partly accounted for the lack of difference observed (42).

Published studies that compared the peritonitis rate of machine-assisted automated PD (APD) and CAPD showed conflicting results (83-91). However, most of these studies were observational rather than randomized trials, and the analysis of these studies is handicapped by failure to report on the connection type in the cyclers used. At present, the choice of $A P D$ versus CAPD should not be based on the risk of peritonitis.

\section{TRAINING PROGRAMS}

- We recommend that the latest ISPD recommendations for teaching PD patients and their caregivers be followed (92).

- We recommend that PD training be conducted by nursing staff with the appropriate qualifications and experience (1C).

The method of training has an important influence on the risk of PD infections (92-103). Much research is needed on the best approach to train patients on the technique of PD to minimize PD-related infections. Unfortunately, high-level evidence guiding how, where, when, and by whom PD training should be performed is lacking (103). Detailed description of the recommended practice of $\mathrm{PD}$ training has been covered in another ISPD guideline $(92,93)$, which each PD program should consult while preparing the trainer and developing a specific curriculum for PD training. In essence, all PD training nurses should receive adequate education to perform training and subsequent further education to update and hone their teaching skills. Each program should have an established curriculum that is followed in teaching the patient the procedure and theory of PD. Testing the patient practical skills at the end of training is essential.

After PD training is completed and patients are started on home PD, a home visit by the PD nurse is often useful in detecting problems with exchange technique, adherence to protocols, and other environmental and behavior issues which increase the risk of peritonitis (104-109). However, the effect of home visits on peritonitis risk has not been tested in a prospective study. One retrospective observational study in 22 pediatric patients reported a non-significant reduction in peritonitis rates following the introduction of home visits (110).

In addition to the initial training, retraining plays an important role in reducing mistakes according to learning specialists $(98,100)$. Previous studies showed that compliance with exchange protocols was significantly associated with peritonitis rate $(98,111)$. Another study found that 6 months after the initiation of PD, most patients took shortcuts, modified the standard exchange method, or did not follow aseptic technique (102). Re-training may reduce peritonitis risk but data are limited to 2 small-scale uncontrolled studies $(98,101)$. A randomized controlled trial has been completed

This single copy is for your personal, non-commercial use only.

For permission to reprint multiple copies or to order presentation-ready

copies for distribution, contact Multimed Inc. at marketing@multi-med.com 
on re-training and the results are pending (112). The indication, optimal time, and content of retraining have not been well defined. Home visits by PD nurses may be a good way to determine which patients require re-training (98). Other indications for re-training are listed in Table $2(14,92)$. Certainly, all patients must be re-trained whenever the equipment to perform PD is changed.

\section{DIALYSIS SOLUTION}

- The committee has no specific recommendation on the choice of dialysis solution for prevention of peritonitis.

Early data suggested that the choice of PD solution may affect peritonitis rates, although the results of published trials are conflicting (113-120). The largest and methodologically most robust randomized trial of neutral-pH, low-glucosedegradation-product (GDP) PD solutions demonstrated that these fluids significantly reduced the occurrence and severity of peritonitis compared with conventional solutions $(117,121)$. A subsequent meta-analysis of 6 randomized controlled trials concluded that the quality of many trials was poor and that trial heterogeneity was high (primarily due to risk of attrition bias), such that the use of neutral-pH PD solutions with reduced GDPs had an uncertain effect on the rate of peritonitis (122). The choice of PD solution should therefore currently not be based on the risk of peritonitis.

\section{EXIT-SITE CARE}

- We recommend daily topical application of antibiotic (mupirocin or gentamicin) cream or ointment to the catheter exit site (1B).

- We recommend prompt treatment of exit-site or catheter tunnel infection to reduce subsequent peritonitis risk (1C).

General measures concerning exit-site care and meticulous hand hygiene during the dialysis exchange have been recommended and should be emphasized during patient training (14). Wearing a face mask during dialysis exchange is optional. A systematic review of 3 trials found that topical disinfection of the exit site with povidone-iodine did not reduce the risk of peritonitis compared to simple soap and water cleansing or no treatment (123). A number of observational studies, randomized controlled trials, and meta-analyses confirm that prophylaxis with daily application of mupirocin cream or ointment to the skin around the exit site is effective in reducing $S$. aureus exit-site infection (ESI) and possibly peritonitis $(37,42,124-131)$. This strategy is further shown in another study to be cost-effective (132). In a meta-analysis of 14 studies (only 3 of which were randomized whilst the remaining 11 were historical cohort studies), topical mupirocin reduced the overall risk of S. aureus infection by $72 \%$, and S. aureus peritonitis by $40 \%$ (127). One retrospective study showed that once weekly topical mupirocin was less effective than more frequent administration (133). A previous prospective
TABLE 2

Indications for PD Re-Training

- Following prolonged hospitalization

- Following peritonitis and/or catheter infection

- Following change in dexterity, vision, or mental acuity

- Following change to another supplier or a different type of connection

- Following other interruption in PD (e.g. period of time on hemodialysis)

$\mathrm{PD}=$ peritoneal dialysis.

study showed that intranasal mupirocin reduced $S$. aureus ESI but not peritonitis (134), but this study has been criticized for excluding patients at highest risk for $\mathrm{S}$. aureus PD-related infections. Intranasal mupirocin treatment is also less well accepted by patients (135). A recent study in pediatric patients suggested that the addition of sodium hypochlorite solution to topical mupirocin may further reduce the rate of peritonitis (136). Mupirocin resistance has been reported, particularly with intermittent use but not daily use (137-140). The longterm implication of mupirocin resistance, however, has not been studied in detail.

With the extensive use of prophylactic agents against S. aureus infections, Pseudomonas species have become a proportionally more common cause of catheter infection (141). A randomized controlled trial showed that daily application of gentamicin cream to the exit site was highly effective in reducing ESIs caused by Pseudomonas species, and was as effective as topical mupirocin in reducing S. aureus ESIs (125). However, 2 subsequent prospective studies found no significant difference in the rates of infection between patients treated with topical gentamicin and mupirocin ointment $(126,142)$. Other observational studies suggested that the change of prophylactic topical antibiotic protocol from mupirocin to gentamicin cream was associated with an increase in ESI caused by Enterobacteriaceae, Pseudomonas species, and probably non-tuberculous mycobacteria $(143,144)$. At present, topical gentamicin should be considered as an acceptable alternative to mupirocin for prophylactic application at the exit site. Unfortunately, the incidence and implications of gentamicin resistance are uncertain.

Other alternative topical antibacterial agents have been tested. A randomized controlled trial found that with standard exit-site care, the rates of catheter infection and peritonitis were similar between patients receiving daily topical application of antibacterial honey to catheter exit site and those treated with intranasal mupirocin ointment (145). Similarly, another randomized trial found that topical triple ointment (polymyxin, bacitracin, and neomycin) was not superior to topical mupirocin in the prophylaxis of PD-related infections (146).

Other prophylactic strategies have been tested. In a randomized controlled trial, peritonitis caused by $S$. aureus or $P$. aeruginosa ESI was markedly reduced with the use of ciprofloxacin otologic solution to the exit site, as compared to

This single copy is for your personal, non-commercial use only.

For permission to reprint multiple copies or to order presentation-ready

copies for distribution, contact Multimed Inc. at marketing@multi-med.com 
simple soap and water cleansing only (147). Two randomized studies comparing oral rifampicin with no treatment both demonstrated significant reductions in peritonitis risk with rifampicin treatment $(148,149)$. In another study, cyclic oral rifampicin and daily topical mupirocin to the exit site were equally effective in reducing the rate of $S$. aureus peritonitis (125). However, adverse effects of rifampicin were more common than those of topical mupirocin (124). Moreover, drug interactions involving rifampicin were a real concern, and rifampicin resistance developed in up to $18 \%$ of cases with repeated usage (150). The use of oral rifampicin for prophylactic purpose is therefore not routinely advocated. Other oral antibiotics, such as trimethoprim/sulfamethoxazole, cephalexin, and ofloxacin were not effective in reducing peritonitis rates (151-153).

There is a strong association between ESI and subsequent peritonitis $(31,154,155)$. Early detection of ESI and prompt management with appropriate antibiotics are logical steps to minimize the risk of subsequent peritonitis $(31,154)$.

\section{BOWEL AND GYNECOLOGICAL SOURCE INFECTIONS}

- We suggest antibiotic prophylaxis prior to colonoscopy (2C) and invasive gynecologic procedures (2D).

Peritoneal dialysis peritonitis commonly follows invasive interventional procedures (e.g. colonoscopy, hysteroscopy, cholecystectomy) in PD patients (156-160). In a single-center study of 97 colonoscopies performed in 77 CAPD patients, peritonitis occurred in $5(6.3 \%)$ of 79 colonoscopies performed without antibiotic prophylaxis and none of 18 colonoscopies performed with antibiotic prophylaxis $(p=0.58)(157)$. Another small retrospective observational study reported that prophylactic antibiotics before most endoscopic interventions, colonoscopy, sigmoidoscopy, cystoscopy, hysteroscopy, and hysteroscopyassisted intrauterine device implantation or removal, but not upper gastrointestinal endoscopy, were associated with a lower peritonitis rate $(0 / 16 \mathrm{vs} 7 / 23, p<0.05)(161)$. A previous systematic review recommended the use of intravenous (IV) ampicillin plus an aminoglycoside, with or without metronidazole, for this purpose (37). However, the optimal antibiotic regimen has not been determined by any clinical study.

Gastrointestinal problems, such as constipation and enteritis, have been reported to be associated with peritonitis due to enteric organisms (162-164). Several studies also note that hypokalemia is associated with an increased risk of enteric peritonitis (165-168). Although there is no compelling evidence to date that treatment of hypokalemia, constipation, or gastroenteritis reduces the rate of peritonitis, such problems, which are common in the PD setting, merit treatment in their own right. Observational data suggest that regular lactulose use reduces peritonitis rate (169).

\section{OTHER MODIFIABLE RISK FACTORS}

A number of other modifiable risk factors for PD peritonitis have been described. Peritonitis has been reported to follow hysteroscopy with biopsy (170) as well as in women with vaginal fistula and leakage (171-174). One retrospective study of 13 gynecological procedures reported a non-significant reduction in peritonitis rates associated with antibiotic prophylaxis $(0 / 4$ vs $5 / 9, p=0.10)$ but had inadequate statistical power (161). Transient bacteremia is common after dental procedures and may lead to peritonitis $(175,176)$. Prophylactic antibiotics (e.g. single oral dose of amoxicillin) before extensive dental procedures may be reasonable.

Prophylactic antibiotics are usually recommended after wet contamination, i.e. if the dialysis solution is infused after contamination, or if the catheter administration set was open for an extended period (14). Most nephrologists give a 2-day course of oral antibiotics after contamination in which dialysis has been infused, but there is no widely accepted standard regimen.

A number of other potentially modifiable risk factors for peritonitis have been reported (19) and are summarized in Table 3. Notably, hypoalbuminemia $(177,178)$, depression (179), and loss of motivation (180) are repeatedly reported as important risk factors, although there are no published data to show that treatment of these problems would reduce peritonitis rate. Similarly, exposure to domestic animals is another risk factor $(181,182)$. Animals should be excluded from the space where the PD is being performed (182). Two observational studies suggested that oral vitamin $D$ therapy was associated with a significantly lower incidence of peritonitis $(183,184)$, but prospective randomized studies are needed to confirm the result.

TABLE 3

Modifiable Risk Factors of Peritonitis*

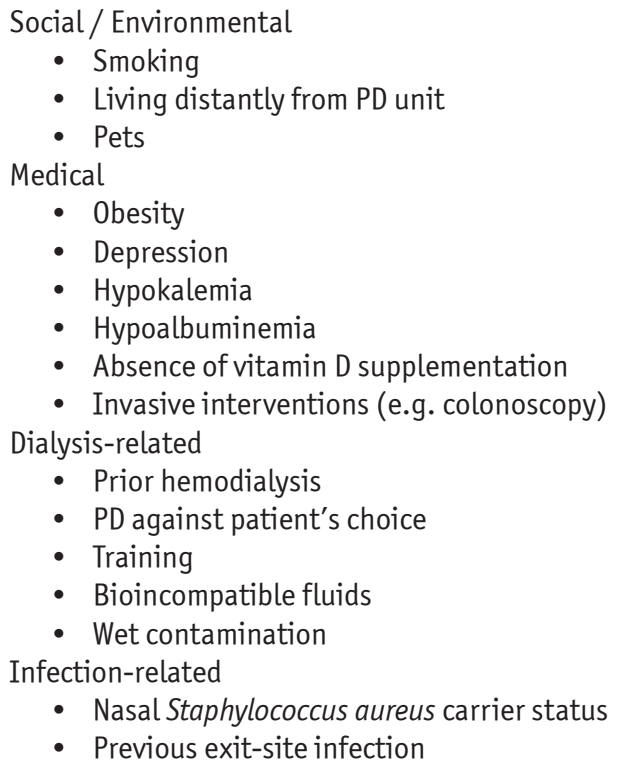

$\mathrm{PD}=$ peritoneal dialysis

* Adapted from Cho Y, et al. (19).

This single copy is for your personal, non-commercial use only. For permission to reprint multiple copies or to order presentation-ready 


\section{CONTINUOUS QUALITY IMPROVEMENT}

- We recommend each PD center have a continuous quality improvement (CQI) program in place to reduce peritonitis rates (1C).

- We suggest that multidisciplinary teams running CQI programs in PD centers meet and review their units' performance metrics regularly $(\mathbf{2 C})$.

A team approach for CQI is the key to a successful PD program (19). The CQI team generally includes nephrologists, nurses, social workers, and dietitians. Regular meetings of the team should be held to examine all PD-related infections and identify the root cause of each episode. The CQI team identifies problems, develops solutions, and evaluates results in an iterative fashion. In essence, if a pattern of infections develops, the team needs to investigate and plan interventions such as retraining, changing equipment, applying new protocols for exit-site care, or managing contamination. Preliminary data suggest that CQI programs reduce peritonitis rates $(17,185,186)$.

\section{SECONDARY PREVENTION}

- We recommend anti-fungal prophylaxis when PD patients receive antibiotic courses to prevent fungal peritonitis (1B).

The majority of fungal peritonitis episodes are preceded by courses of antibiotics (187-189). A number of observational studies and randomized trials have examined the use of either oral nystatin or fluconazole as prophylaxis during antibiotic therapy (190-197). In essence, 2 randomized controlled trials $(192,197)$ and a systematic review $(37)$ showed a significant benefit. Most of the other reports on the prophylactic use of antifungals during antibiotic administration were non-randomized studies and have yielded a mixed result. Unfortunately, nystatin is not available in some countries. Observational data and 1 randomized controlled trial showed that prophylactic fluconazole is effective (197-200). However, there are potential problems (e.g. drug interactions, emergence of resistant strains) with fluconazole prophylaxis that should also be considered.

The CQI program may also have a role in secondary prevention. For each peritonitis episode, a root-cause analysis should be done to determine the etiology, and, whenever possible, an intervention directed against any reversible risk factor should be made to prevent another episode. For example, peritonitis episodes caused by coagulase-negative Staphylococcal species are associated with touch contamination, while Staphylococcus aureus infections have been associated with touch contamination or catheter infections. Identification of etiology may involve review of the exchange technique. Retraining is sometimes necessary. Replacement of the catheter may be considered in patients with relapsing or repeat peritonitis $(201,202)$ and has been reported to be more effective than urokinase therapy (203). When PD effluent clears up after antibiotic treatment, catheter removal and re-insertion can be performed as a single procedure without the need for temporary hemodialysis $(202,204,205)$.

\section{INITIAL PRESENTATION AND MANAGEMENT OF PERITONITIS}

The algorithm of initial management for PD patients presenting with a clinical diagnosis is summarized in Figure 1.

\section{Clinical Presentation and Diagnosis of Peritonitis}

- We recommend that peritonitis always be diagnosed when at least 2 of the following are present: (1) clinical features consistent with peritonitis, i.e. abdominal pain and/or cloudy dialysis effluent; (2) dialysis effluent white cell count $>100 / \mu \mathrm{L}$ or $>0.1 \times 10^{9} / \mathrm{L}$ (after a dwell time of at least 2 hours), with $>50 \%$ polymorphonuclear; and (3) positive dialysis effluent culture (1C).

- We recommend that PD patients presenting with cloudy effluent be presumed to have peritonitis and treated as such until the diagnosis can be confirmed or excluded (1C).

- We recommend that PD effluent be tested for cell count, differential, Gram stain, and culture whenever peritonitis is suspected (1C).

Patients with peritonitis usually present with cloudy PD effluent and abdominal pain. Cloudy effluent almost always represents infectious peritonitis, although there are other differential diagnoses (Table 4) (206). Some patients present with cloudy effluent but no or minimal abdominal pain. On the other hand, peritonitis should also be included in the differential diagnosis of the PD patient presenting with abdominal pain, even if the effluent is clear. In addition to the presenting symptoms, the patient should be questioned about any recent contamination, accidental disconnection, endoscopic or gynecologic procedure, as well as the presence of constipation or

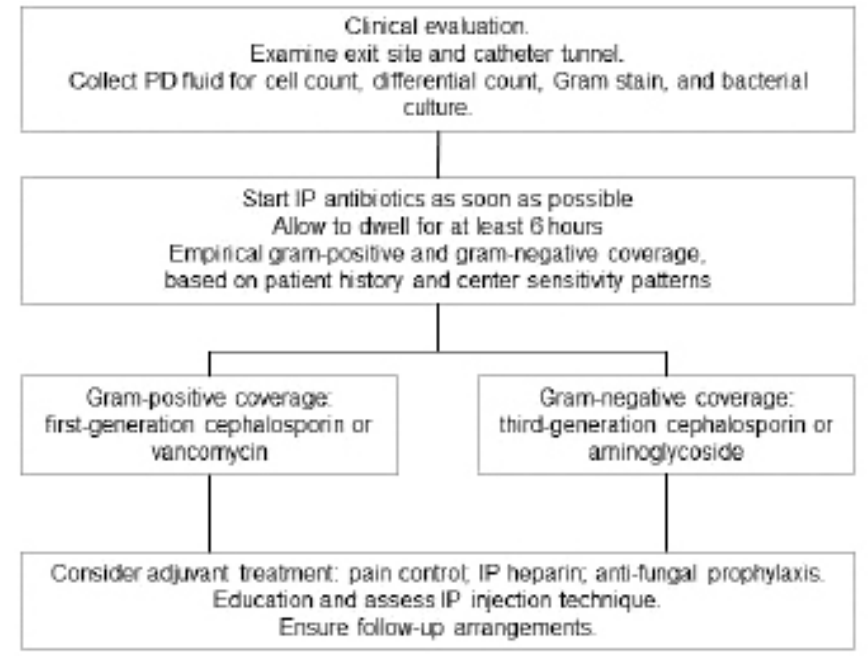

Figure 1 - Initial management of peritonitis. IP = intra-peritoneal.

This single copy is for your personal, non-commercial use only. For permission to reprint multiple copies or to order presentation-ready copies for distribution, contact Multimed Inc. at marketing@multi-med.com 
TABLE 4

Differential Diagnosis of Cloudy Effluent

- Culture-positive infectious peritonitis

- Infectious peritonitis with sterile cultures

- Chemical peritonitis

- Calcium channel blockers

- Eosinophilia of the effluent

- Hemoperitoneum

- Malignancy (rare)

- Chylous effluent (rare)

- Specimen taken from "dry" abdomen

diarrhea. In addition, the patient should be questioned about past history of peritonitis and ESI.

On physical examination, abdominal tenderness is typically generalized and is occasionally associated with rebound. Localized pain or tenderness should raise the suspicion of an underlying surgical pathology. Physical examination should also include a careful inspection of the catheter tunnel and exit site. Any discharge from the exit site should be cultured. The degree of abdominal pain and tenderness are important factors in deciding whether a patient requires hospital admission. In general, patients with minimal pain could be treated on an outpatient basis with intraperitoneal (IP) antibiotic therapy if this can be arranged. Follow-up within 3 days is advisable to confirm resolution and appropriateness of the antibiotic choice.

When peritonitis is suspected, dialysis effluent should be drained, carefully inspected, and sent for cell count with differential, Gram stain, and culture (207). An effluent cell count with white blood cells $(\mathrm{WBC})>100 / \mu \mathrm{L}$ (after a dwell time of at least 2 hours), with $>50 \% \mathrm{PMN}$, is highly suggestive of peritonitis (208). Abdominal $X$ ray is generally not necessary. Peripheral blood culture is usually not necessary but should be obtained if the patient is clinically septic. To prevent delay in treatment, antibiotic therapy (see below) should be initiated once the appropriate dialysis effluent specimens have been collected, without waiting for the results of laboratory testing.

The WBC count in the effluent depends in part on the length of the dwell. For patients on APD with rapid cycle treatment, the clinician should use the percentage of PMN rather than the absolute WBC count to diagnose peritonitis, and a proportion above $50 \%$ PMN is strong evidence of peritonitis, even if the absolute WBC count is less than $100 / \mu \mathrm{L}$ (208). On the other hand, APD patients without a daytime exchange who present with abdominal pain during the daytime may have no effluent to drain. In this case, $1 \mathrm{~L}$ of dialysis solution should be infused, dwelled for 1 to 2 hours, and then drained for inspection and laboratory testing.

Some PD patients live far away from medical facilities and cannot be seen expeditiously after the onset of symptoms. Since prompt initiation of therapy for peritonitis is critical, this necessitates reliance on immediate patient reporting of symptoms to the center, and then initiating IP antibiotics in the home setting. Such an approach requires that the patients be trained in this technique and that antibiotics be kept at home. Whenever possible, cultures should be obtained either at a local facility or by having blood culture bottles kept at home for use. However, it is important that no one accesses the PD catheter without the appropriate training or equipment, which is often the case in smaller emergency departments. In this case the patient can drain his/her abdomen and provide the cloudy effluent for culture. Alternatively, the patient may place the cloudy effluent bag in the refrigerator until they can bring the sample to their PD center. The benefit of selfinitiated treatment, however, should be carefully balanced against the potential problems of over-diagnosis and habitual misuse of antibiotics.

\section{Identification of Causative Organism}

- We recommend that the blood-culture bottle be the preferred technique for bacterial culture of PD effluent (1C).

- We suggest that sampling and culture methods be reviewed and improved if more than $15 \%$ of peritonitis episodes are culture-negative (2C).

Gram stain of the PD effluent should be performed even though the result is often negative (209). The yield on the Gram stain is increased if it is performed on centrifuged specimens. An appropriate method of culturing PD effluent is the most important step in establishing the causative organism. In some specialized centers, one could achieve less than $10 \%$ rate of culture negative peritonitis. Identification of the organism and subsequent antibiotic sensitivities help to guide the choice of antibiotic, and the type of organism often indicates the possible source of infection. Bedside inoculation of $5-10 \mathrm{~mL}$ effluent in 2 (aerobic and anaerobic) blood-culture bottles has a reasonable sensitivity, and the culture-negative rate is typically around $10-20 \%$. $(210,211)$. The yield of peritoneal fluid culture is enhanced by inoculating the fluid directly into rapid blood-culture bottle kits (e.g. BACTEC, Kent, UK; SeptiChek, Roche Diagnostics, Basel, Switzerland; BacT/Alert, Biomerieux, Inc., Basingstoke, UK), centrifuging PD fluid and culturing the pellet, or the lysis centrifugation technique compared to inoculation into standard blood-culture bottles. Specifically, centrifugation of $50 \mathrm{~mL}$ PD effluent at 3,000 g for 15 minutes, followed by resuspension of the sediment in $3-5 \mathrm{~mL}$ supernatant and inoculation on solid culture media or standard blood-culture media, increases the yield by 5 to 10 times but is more cumbersome $(212,213)$. The combination of water lysis, Tween-80 blood agar and Triton-X treatment of the PD effluent is also a sensitive culture method (214). The specimens should arrive at the laboratory within 6 hours. If immediate delivery to the laboratory is not possible, the inoculated culture bottles should ideally be incubated at $37^{\circ} \mathrm{C}$. The solid media should be incubated in aerobic, microaerophilic, and anaerobic environments.

The speed with which bacteriological diagnosis can be established is very important. Concentration methods do not

This single copy is for your personal, non-commercial use only.

For permission to reprint multiple copies or to order presentation-ready

copies for distribution, contact Multimed Inc. at marketing@multi-med.com 
only facilitate microbial identification, but also reduce the time needed for a positive culture. In over $75 \%$ of cases, microbiologic diagnosis can be established in less than 3 days. When the causative microorganism has been identified, subsequent cultures for monitoring may be performed by only inoculating the effluent in blood-culture bottles.

When cultures remain negative after $3-5$ days of incubation, PD effluent should be sent for repeat cell count, differential count, fungal, and mycobacterial culture. In addition, subculture on media with aerobic, anaerobic, and microaerophilic incubation conditions for a further $3-4$ days may help to identify slow-growing fastidious bacteria and yeasts that are undetectable in some automated culture systems.

\section{Other Novel Diagnostic Techniques}

- We suggest that there is insufficient evidence to currently support the use of novel techniques for the diagnosis of peritonitis (2D).

A number of novel diagnostic techniques have been explored for the early diagnosis of peritonitis, including leukocyte esterase reagent strips, biomarker assays (matrix metalloproteinase- 8 and -9 , neutrophil gelatinase-associated lipocalin and procalcitonin), polymerase chain reaction (PCR) for bacterial-derived DNA fragments, 16S rRNA gene sequencing, matrix-assisted laser desorption ionization-time of flight (MALDI-TOF), and pathogen-specific "immune fingerprints" (215-226). However, none of them has been proved to be superior to conventional techniques. Other novel techniques have also been developed for rapid species identification and the determination of resistant organisms (e.g. methicillin-resistant S. aureus (MRSA), vancomycin-resistant enterococci, Klebsiella pneumoniae carbapenemase), which may allow more rapid initiation of focused antimicrobial therapy of resistant pathogens, but their role in the management of PD-related peritonitis remain unclear. Further studies in this area are necessary.

\section{Empiric Antibiotic Selection}

- We recommend that empirical antibiotic therapy be initiated as soon as possible after appropriate microbiological specimens have been obtained (1C).

- We recommend that empirical antibiotic regimens be centerspecific and cover both gram-positive and gram-negative organisms (1C).

- We recommend that gram-positive organisms be covered by vancomycin or a first generation cephalosporin and gramnegative organisms by a third-generation cephalosporin or an aminoglycoside (1B).

Antibiotic treatment should aim for rapid resolution of inflammation and preservation of the peritoneal membrane function. No antibiotic regimen has been proved to be superior to others as empirical treatment (203), although the combination of a glycopeptide (vancomycin or teicoplanin) plus ceftazidime was considered to be superior to other regimens in a proportional meta-analysis (227).

For gram-positive coverage, several studies compared a first-generation cephalosporin with a glycopeptide-based regimen (228-231). When analyzed as a whole, glycopeptide-based regimens result in a higher complete cure rate, but there is no difference in the rate of primary treatment failure, relapse, or catheter removal (203). A systematic review noted that the result was largely influenced by 1 study, in which the dosage of cefazolin was substantially lower than current recommendations (228). Other studies found no difference in cure rates for vancomycin and cefazolin when an appropriate cephalosporin dose was used $(228,230,231)$. Nonetheless, some PD units have a high rate of methicillin-resistant organisms and vancomycin may be preferable for empirical gram-positive coverage (232), although it remains controversial what threshold prevalence of methicillin resistance would justify the routine empirical use of vancomycin as gram-positive coverage.

For the coverage of gram-negative organisms, previous studies have shown that aminoglycosides (e.g. gentamicin or netilmicin) (233), ceftazidime (233), cefepime (234), or a carbapenem $(235,236)$ are all effective. Cefepime per se has reasonable activity against gram-positive bacteria and monotherapy may be feasible (234). Fluoroquinolones could also be used if supported by the local antimicrobial susceptibilities of antibiotic sensitivities (237-241). For patients allergic to cephalosporins, aztreonam is also a possible alternative (242-244). In a randomized controlled study, IP netilmicin and ceftazidime had similar efficacy to empirical gram-negative coverage (233). Short-term aminoglycoside treatment is inexpensive, safe, and provides good gram-negative coverage. There is no evidence that short courses of aminoglycosides accelerate the loss of residual renal function (233,245-247). However, repeated or prolonged aminoglycoside treatment (more than 3 weeks) was associated with a high incidence of vestibular toxicity or oto-toxicity and should be avoided $(248,249)$.

In addition to the above combinations, a variety of regimens have been shown by prospective trials to have acceptable results (250). For example, imipenem/cilastatin monotherapy was as effective as cefazolin plus ceftazidime (236), and cefepime was as effective as vancomycin plus netilmicin (234). In another study, oral ofloxacin alone was not inferior to cephalothin plus tobramycin (241), but the effectiveness of ciprofloxacin monotherapy has declined markedly in the past decade (251).

It is important to note that antibiotic resistance may develop with extensive empiric use of broad-spectrum cephalosporins or fluoroquinolones. The prevalence of resistant pathogens in each program should be regularly monitored and the choice of empirical antibiotic may need to be changed accordingly.

\section{Dosage of Antibiotics}

- We recommend that IP antibiotics be the preferred route of administration unless the patient has features of systemic sepsis (1B). 
- We suggest that IP aminoglycoside be administered as daily intermittent dosing (2B).

- We recommend that prolonged courses of IP aminoglycoside be avoided (1C).

- We suggest that IP vancomycin be administered intermittently and the serum vancomycin level be kept above $15 \mu \mathrm{g} /$ $\mathrm{mL}(2 \mathrm{C})$.

- We suggest that IP cephalosporin be administered either continuously (in each exchange) or on a daily intermittent basis $(2 \mathrm{C})$.

The recommended dosage of antibiotics for the treatment of PD-related peritonitis is summarized in Tables 5 and 6 (236$239,252-303)$. However, the recommended dosages of many antibiotics are based on published clinical experience rather than formal pharmacokinetic studies. It was recommended previously that for patients with substantial residual renal function, the dose of antibiotics that have renal excretion needs to be adjusted $(12,13)$. However, recent studies suggest that such adjustments are not necessary $(284,304)$.

In general, IP dosing results in high IP drug levels and is preferable to IV administration. Moreover, IP dosing avoids venipuncture and could be done by the patient at home after appropriate training. Although IV vancomycin is reasonably successful as empirical gram-positive coverage (237), previous studies have shown that IV vancomycin resulted in a significantly higher rate of primary treatment failure than IP administration $(203,305)$. Intraperitoneal antibiotics should be added using sterile technique, such as placing povidone iodine, rubbing with alcohol $70 \%$ strip, or chlorhexidine on the medication port for 5 minutes prior to insertion of the needle through the port.

\section{TABLE 5}

Intraperitoneal Antibiotic Dosing Recommendations for Treatment of Peritonitis

\begin{tabular}{|c|c|c|}
\hline & Intermittent (1 exchange daily) & Continuous (all exchanges) \\
\hline \multicolumn{3}{|l|}{ Aminoglycosides } \\
\hline Amikacin & 2 mg/kg daily (252) & LD 25 mg/L, MD 12 mg/L (253) \\
\hline Gentamicin & 0.6 mg/kg daily (254) & LD 8 mg/L, MD 4 mg/L $(255,256)$ \\
\hline Netilmicin & 0.6 mg/kg daily (233) & MD $10 \mathrm{mg} / \mathrm{L}(257)$ \\
\hline Tobramycin & 0.6 mg/kg daily (253) & LD 3 mg/kg, MD $0.3 \mathrm{mg} / \mathrm{kg}(258,259)$ \\
\hline \multicolumn{3}{|l|}{ Cephalosporins } \\
\hline Cefazolin & $15-20 \mathrm{mg} / \mathrm{kg}$ daily $(260,261)$ & LD 500 mg/L, MD 125 mg/L (254) \\
\hline Cefepime & $1,000 \mathrm{mg}$ daily $(262,263)$ & LD $250-500 \mathrm{mg} / \mathrm{L}, \mathrm{MD} 100-125 \mathrm{mg} / \mathrm{L}(262,263)$ \\
\hline Cefoperazone & no data & LD 500 mg/L, MD 62.5-125 mg/L $(264,265)$ \\
\hline Cefotaxime & $500-1,000$ mg daily (266) & no data \\
\hline Ceftazidime & $1,000-1,500 \mathrm{mg}$ daily $(267,268)$ & LD 500 mg/L, MD 125 mg/L (236) \\
\hline Ceftriaxone & $1,000 \mathrm{mg}$ daily (269) & no data \\
\hline \multicolumn{3}{|l|}{ Penicillins } \\
\hline Penicillin G & no data & LD 50,000 unit/L, MD 25,000 unit/L (270) \\
\hline Amoxicillin & no data & MD $150 \mathrm{mg} / \mathrm{L}(271)$ \\
\hline Ampicillin & no data & MD $125 \mathrm{mg} / \mathrm{L}(272,273)$ \\
\hline Ampicillin/Sulbactam & 2 gm/1 gm every 12 hours (274) & LD 750-100 mg/L, MD 100 mg/L (253) \\
\hline Piperacillin/Tazobactam & no data & LD $4 \mathrm{gm} / 0.5 \mathrm{gm}$, MD $1 \mathrm{gm} / 0.125 \mathrm{gm}$ (275) \\
\hline \multicolumn{3}{|l|}{ Others } \\
\hline Aztreonam & 2 gm daily (242) & LD 1,000 mg/L, MD $250 \mathrm{mg} / \mathrm{L}(243,244)$ \\
\hline Ciprofloxacin & no data & MD $50 \mathrm{mg} / \mathrm{L}(276)$ \\
\hline Clindamycin & no data & MD $600 \mathrm{mg} / \mathrm{bag}(277)$ \\
\hline Daptomycin & no data & LD 100 mg/L, MD 20 mg/L (278) \\
\hline Imipenem/Cilastatin & $500 \mathrm{mg}$ in alternate exchange (244) & LD $250 \mathrm{mg} / \mathrm{L}, \mathrm{MD} 50 \mathrm{mg} / \mathrm{L}(236)$ \\
\hline Ofloxacin & no data & LD 200 mg, MD 25 mg/L (279) \\
\hline Polymyxin B & no data & MD 300,000 unit $(30 \mathrm{mg}) / \mathrm{bag}(280)$ \\
\hline Quinupristin/Dalfopristin & $25 \mathrm{mg} / \mathrm{L}$ in alternate exchange $\mathrm{e}^{\mathrm{a}}(281)$ & no data \\
\hline Meropenem & 1 gm daily (282) & no data \\
\hline Teicoplanin & $15 \mathrm{mg} / \mathrm{kg}$ every 5 days (283) & LD 400 mg/bag, MD 20 mg/bag (229) \\
\hline Vancomycin & $15-30 \mathrm{mg} / \mathrm{kg}$ every 5-7 days ${ }^{\mathrm{b}}(284)$ & LD 30 mg/kg, MD 1.5 mg/kg/bag (285) \\
\hline \multicolumn{3}{|l|}{ Antifungals } \\
\hline Fluconazole & IP 200 mg every 24 to 48 hours (286) & no data \\
\hline Voriconazole & IP $2.5 \mathrm{mg} / \mathrm{kg}$ daily (287) & no data \\
\hline
\end{tabular}

$\mathrm{LD}=$ loading dose in $\mathrm{mg} ; \mathrm{MD}=$ maintenance dose in $\mathrm{mg} ; \mathrm{IP}=$ intraperitoneal; $\mathrm{APD}=$ automated peritoneal dialysis.

a Given in conjunction with $500 \mathrm{mg}$ intravenous twice daily (281).

b Supplemental doses may be needed for APD patients.

This single copy is for your personal, non-commercial use only. 
TABLE 6

Systemic Antibiotic Dosing Recommendations for Treatment of Peritonitis

\begin{tabular}{lc}
\hline \multicolumn{1}{c}{ Drug } & Dosing \\
\hline Anti-bacterials & \\
Ciprofloxacin (237) & oral $250 \mathrm{mg} \mathrm{BD}$ \\
Colistin (288) & IV $300 \mathrm{mg}$ loading, then \\
& $150-200 \mathrm{mg}$ dailyb \\
Ertapenem (289) & IV $500 \mathrm{mg}$ daily \\
Levofloxacin (239) & oral $250 \mathrm{mg}$ daily \\
Linezolid (290-292) & IV or oral $600 \mathrm{mg}$ BD \\
Moxifloxacin (293) & oral $400 \mathrm{mg}$ daily \\
Rifampicin (294,295) & $450 \mathrm{mg}$ daily for BW $<50 \mathrm{~kg} ;$ \\
& $600 \mathrm{mg}$ daily for BW $\geq 50 \mathrm{~kg}$ \\
Trimethoprim/ & oral $160 \mathrm{mg} / 800 \mathrm{mg}$ BD \\
Sulfamethoxazole (252) & \\
Anti-fungals & \\
Amphotericin (296) & IV test dose $1 \mathrm{mg} ;$ starting dose \\
& $0.1 \mathrm{mg} / \mathrm{kg} /$ day over 6 hours; \\
increased to target dose \\
Caspofungin (297,298) & IV $70 \mathrm{mg}$ loading, then $50 \mathrm{mg}$ daily \\
Fluconazole (299) & oral $200 \mathrm{mg}$ loading, then \\
Flucytosine (296) & $50-100 \mathrm{mg}$ daily \\
Posaconazole (300) & oral $1 \mathrm{gm} /$ day \\
Voriconazole (301-303) & IV $400 \mathrm{mg}$ every 12 hours \\
oral $200 \mathrm{mg}$ every 12 hours
\end{tabular}

$\mathrm{BD}=$ twice a day; $\mathrm{IV}=$ intravenous; $\mathrm{BW}=$ body weight.

a Ciprofloxacin $500 \mathrm{mg} \mathrm{BD}$ may be needed if residual glomerular filtration rate is above $5 \mathrm{~mL} / \mathrm{min}$.

${ }^{\mathrm{b}}$ Expressed as colistin base activity (CBA).

Intraperitoneal antibiotics can be given as continuous (i.e. in each exchange) or intermittent dosing (i.e. once daily) (306-310). In intermittent dosing, the antibiotic-containing dialysis solution must be allowed to dwell for at least 6 hours to allow adequate absorption. Many antibiotics have significantly enhanced absorption during peritonitis, which permits reentry into the peritoneal cavity during subsequent PD cycles.

For vancomycin, about $50 \%$ of IP dosing is absorbed when there is no peritonitis, but nearly $90 \%$ in the presence of peritonitis $(304,306)$. A randomized controlled trial in children found that intermittent dosing of vancomycin is as efficacious as continuous dosing (311). The role of monitoring serum vancomycin levels is controversial $(284,312)$. In general, a dosing interval of every 4 to 5 days would keep serum trough levels above $15 \mu \mathrm{g} / \mathrm{mL}$, but there is substantial inter-individual variability $(284,304)$. Re-dosing is probably appropriate when serum vancomycin levels are below $15 \mu \mathrm{g} / \mathrm{mL}(304,313,314)$.

At the dosage currently recommended, the peak gentamicin concentration in dialysis solution is at least 8 times the minimal inhibitory concentration (MIC) of the likely pathogens (315). Two studies showed that once-daily gentamicin is as effective as continuous dosing for CAPD patients $(256,316)$. However, systemic absorption of intermittent IP gentamicin is highly variable and depends on the peritoneal transport characteristics (315), and the high systemic absorption of gentamicin in patients with peritonitis and prolonged plasma elimination half-life may lead to systemic accumulation and subsequent toxicity (315). At the currently recommended dosing regimen, serum gentamicin levels might be excessive in over $50 \%$ of patients (304), and higher serum levels were not associated with better cure rates (304). However, there is no firm evidence that monitoring aminoglycoside levels mitigates toxicity risk or enhances efficacy (314). The serum gentamicin level on day 2 is not associated with treatment efficacy or adverse effects during short-course therapy (317). Studies on the relationship between serum aminoglycoside levels following IP administration and the subsequent risk of ototoxicity are conflicting and often show a negative result (318-321). Taken together, serum aminoglycoside level monitoring for PD patients receiving IP treatment seems to play a small role. Once the causative bacteria are identified and sensitivity confirmed, early switch from empirical aminoglycoside to other agents (e.g. third-generation cephalosporin) could minimize the risk of ototoxicity (314).

For cephalosporins, there are few data on whether continuous dosing is more efficacious than intermittent dosing. In CAPD patients, IP cefazolin $500 \mathrm{mg} / \mathrm{L}$ once daily results in acceptable 24-hour levels in the PD fluid (308). Although continuous IP ceftazidime is traditionally given at the same dose as cefazolin (13), once-daily IP ceftazidime at a dose of $20 \mathrm{mg} / \mathrm{kg}$ once daily may not provide adequately therapeutic levels in dialysis solution throughout 24 hours (267). One pharmacokinetic study showed that a loading dose of $3 \mathrm{~g}$ is necessary to achieve an adequate dialysis solution drug concentration (322), which could be followed by maintenance IP dosing of $1 \mathrm{gm}$ q24h or $2 \mathrm{gm} \mathrm{q48h} \mathrm{(322).}$

Oral administration of fluoroquinolones is commonly used alone or in combination with other antibiotics (237). Oral ciprofloxacin and moxifloxacin reach adequate levels within the peritoneum $(293,323)$. However, adequate IP levels may require a day to be reached, and some oral phosphate binders can bind fluoroquinolones and reduce their bioavailability $(324,325)$. Ciprofloxacin is effective against Pseudomonas species, while moxifloxacin has better coverage of gram-positive organisms. A systematic review of 2 low-quality studies concluded that IP fluoroquinolone may achieve better complete cure rate than oral treatment, although failure rates were high in both arms of these studies $(203,276,279)$.

\section{Antibiotic Delivery and Stability}

The stability and compatibility of various antibiotics for IP administration was reviewed previously (326). In essence, vancomycin, aminoglycosides, and cephalosporins can be mixed in the same dialysis solution bag without loss of bioactivity. Aminoglycosides and cephalosporins can be added to the same bag, although aminoglycoside should not be added to the same bag with penicillins because of chemical incompatibility (326). For any antibiotics that are to be admixed, separate syringes

This single copy is for your personal, non-commercial use only. For permission to reprint multiple copies or to order presentation-ready copies for distribution, contact Multimed Inc. at marketing@multi-med.com 
must be used for adding the antibiotics. Although vancomycin and ceftazidime are compatible when added to dialysis solutions ( $1 \mathrm{~L}$ total volume or greater), they are incompatible if combined in the same syringe or added to an empty dialysis solution bag for reinfusion into the patient.

Antibiotics are stable for variable times after being added to the PD solution (327). Vancomycin is stable for 28 days in dialysis solutions stored at room temperature, although higher ambient temperatures will reduce the duration of stability. Gentamicin is stable for 14 days both at room temperature and under refrigeration, but the duration of stability is reduced by admixture with heparin. Cefazolin is stable for 8 days at room temperature or for 14 days if refrigerated; addition of heparin has no adverse influence. Ceftazidime is stable for 4 days at room temperature or 7 days if refrigerated. Cefepime is stable for 14 days if the solution is refrigerated (328).

Data on the stability of various new antibiotics and PD solutions are limited and often fragmented (329-332). Clinicians should remain alert for new studies in this area. In general, icodextrin-based PD solutions are compatible with vancomycin, cefazolin, ceftazidime, and gentamicin $(329,333,334)$. When premixed in icodextrin solution, these antibiotics are least stable at $37^{\circ} \mathrm{C}$ and most stable at $4^{\circ} \mathrm{C}$, permitting storage for 14 days when refrigerated and pre-warming to body temperature prior to administration (334).

\section{Special Considerations for APD}

There is a substantial knowledge gap regarding the antibiotic dosing requirements for the treatment of peritonitis in APD patients. In general, the intermittent IP dosing listed in Table 4 could be given in the day dwell of APD patients. However, extrapolation of data from CAPD to APD may result in significant under-dosing in APD patients because rapid exchanges in APD may lead to inadequate time to achieve therapeutic levels when antibiotics are given IP intermittently, and APD results in a higher peritoneal clearance of antibiotics than CAPD. This problem is particularly obvious amongst high peritoneal transporters. Alternatively, APD patients who develop peritonitis may switch temporarily to CAPD. However, it is not always practical to switch because patients may not be familiar with the exchange technique, and the supplies for CAPD may not be immediately available. A recent report also found that this practice is associated with an increased risk of technique failure and fluid overload (335). Resetting the cycler to permit a longer exchange time in such cases is a logical alternative, but the efficacy of this approach has not been well studied.

For patients who remain on rapid-cycle APD, there are few data concerning efficacy of first-generation cephalosporins given intermittently. For APD patients treated with cephalosporins added to the daytime exchange only, the nighttime IP levels are below the MIC of most organisms. Adding firstgeneration cephalosporin to each exchange would appear to be the safest approach. Although the IP vancomycin level may be low in APD patients due to slow diffusion from blood to dialysis solution, a randomized controlled trial in children showed that intermittent dosing of vancomycin was as effective as continuous dosing in children receiving APD (311). Vancomycin can probably be given intermittently for APD patients. Oral ciprofloxacin can also achieve adequate levels within the peritoneum in APD patients (323). In a retrospective, single-center observational cohort study of 508 episodes of PD-associated peritonitis in 208 patients, no differences in relapse rates, mortality, or the combined end-point of mortality and catheter removal were observed between APD and CAPD patients continuing their own PD modality during continuous IP antibiotic treatment in each PD exchange, although elevated dialysis effluent leukocyte counts and antibiotic treatment durations were longer in the former (90).

\section{Adjunctive Treatments}

Some patients with PD-related peritonitis could be managed on an outpatient basis. The decision to hospitalize a patient depends on many factors, including hemodynamic status of the patient, severity of signs and symptoms, and, for APD patients, the type of treatment schedule chosen, as well as the ability to provide IP antibiotics as an outpatient and the reliability of the patient. The rationale for anti-fungal prophylaxis has been discussed in a previous section (see Secondary Prevention, above).

Patients with cloudy effluent may benefit from the addition of heparin 500 units/L IP to prevent occlusion of the catheter by fibrin. Depending on the severity of symptoms, some patients would require analgesics for pain control. At the initial presentation and before IP antibiotics are initiated, 1 or 2 rapid PD exchanges are often performed for pain relief, although there are no data supporting this approach. A randomized controlled trial showed that more extensive rapidcycle peritoneal lavage during the first 24 hours of peritonitis did not affect the rate of complete cure or relapse as compared to the usual practice of 2 rapid exchange cycles (336).

Intraperitoneal urokinase has been advocated for the treatment of biofilm, which may be the cause of refractory or relapsing peritonitis. A retrospective study found that IP urokinase and oral rifampicin, in addition to conventional antibiotics, resulted in catheter salvage in $64 \%$ of cases with persisting asymptomatic infection following coagulase-negative staphylococcus peritonitis (337). Randomized controlled trials, however, failed to show any benefit of IP urokinase for the treatment of refractory peritonitis (338-340). The rates of complete cure, catheter removal, or relapsing episode, as well as overall mortality were not affected by adjunctive treatment with IP urokinase. In contrast, 1 randomized controlled study showed that simultaneous catheter removal and replacement was superior to IP urokinase in reducing relapsing peritonitis episodes (341).

Peritoneal permeability to water, glucose, and proteins typically increases during peritonitis. Reduction in ultrafiltration is commonly observed, and fluid overload is a frequent complication. Temporary use of hypertonic exchanges and short dwell times may be needed to maintain adequate fluid

This single copy is for your personal, non-commercial use only.

For permission to reprint multiple copies or to order presentation-ready

copies for distribution, contact Multimed Inc. at marketing@multi-med.com 
removal. Temporary use of icodextrin solution may prevent fluid overload in PD patients with acute peritonitis (342). Because of rapid glucose absorption, glycemic control may worsen in diabetic patients. Blood glucose monitoring with appropriate adjustments of insulin dosage may be needed. Protein loss during peritonitis is also increased. Screening for malnutrition should be undertaken in patients with prolonged peritoneal inflammation.

\section{SUBSEQUENT MANAGEMENT OF PERITONITIS}

- We recommend that antibiotic therapy be adjusted to narrow-spectrum agents, as appropriate, once culture results and sensitivities are known. (1C).

The management algorithms for gram-positive cocci and gram-negative bacilli identified in dialysis effluent are summarized in Figures 2 and 3, respectively. Within 48 hours of initiating therapy, most patients with PD-related peritonitis will show considerable clinical improvement. The effluent should be visually inspected regularly to determine whether clearing is occurring. If there is no improvement after 48 hours, cell counts and repeat cultures should be performed. In addition, monitoring of WBC count in PD effluent may predict treatment response. A retrospective study showed that dialysis effluent WBC count $\geq 1,090 / \mathrm{mm}^{3}$ on day 3 was an independent prognostic marker for treatment failure (343).

\section{Refractory Peritonitis}

- We recommend that the PD catheter be removed promptly in refractory peritonitis episodes, defined as failure of the PD effluent to clear up after 5 days of appropriate antibiotics (1C).

After initiation of antibiotic treatment, there is usually clinical improvement in 72 hours. Refractory peritonitis is defined as failure of the PD effluent to clear up after 5 days of appropriate antibiotics (Table 7). Catheter removal is indicated in case of refractory peritonitis, or earlier if the patient's clinical condition is deteriorating, in order to preserve the peritoneum for future PD as well as preventing morbidity and mortality. Prolonged attempts to treat refractory peritonitis by antibiotics without catheter removal are associated with extended hospital stay, peritoneal membrane damage, increased risk of fungal peritonitis, and excessive mortality (344).

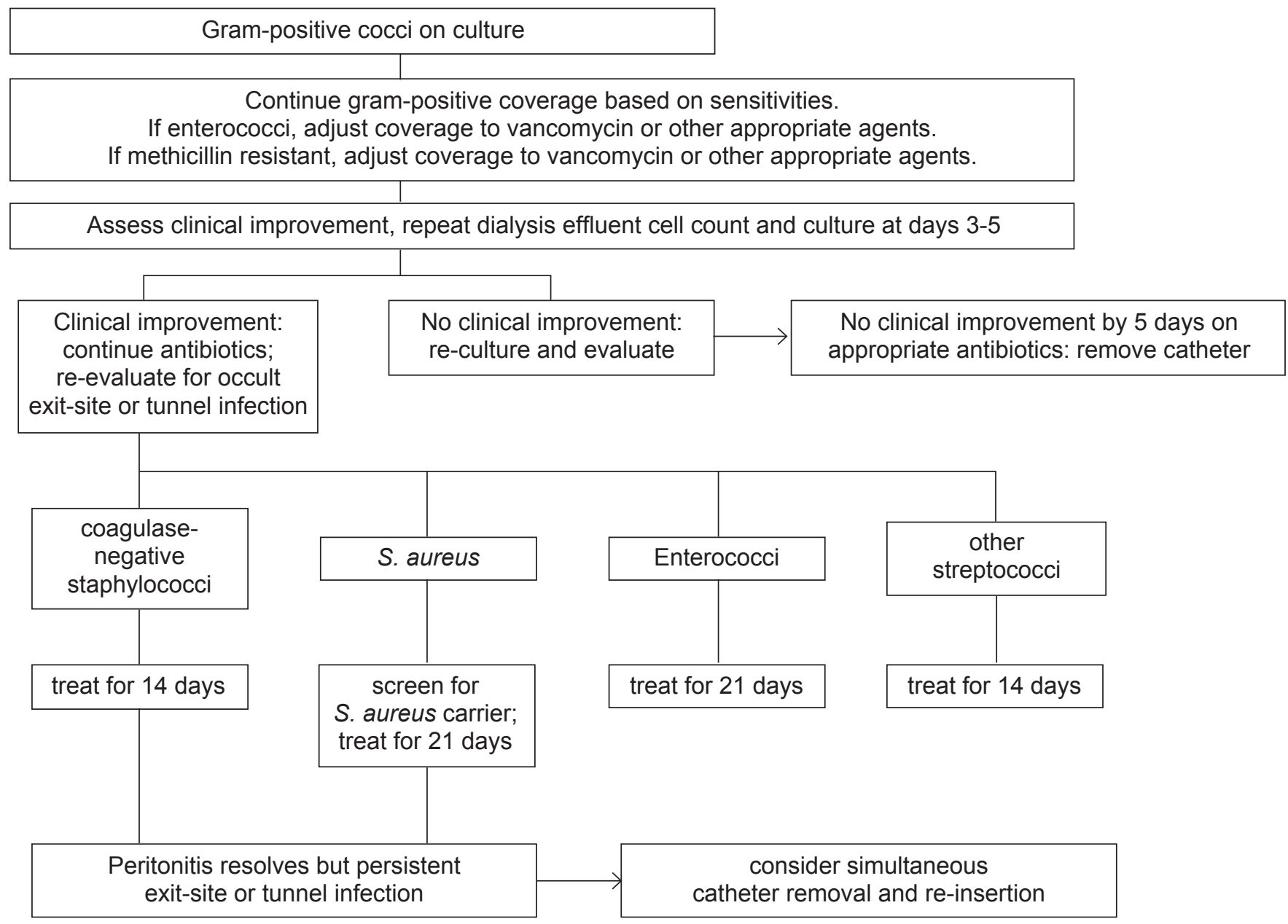

Figure 2-Management algorithm for gram-positive cocci identified in dialysis effluent. 
Gram-negative bacilli or mixed bacterial growth on culture

Figure 3 - Management algorithm for gram-negative bacilli or mixed bacterial growth identified in dialysis effluent. * Trimethoprim/sulfamethoxazole is preferred for Stenotrophomonas species.

\section{Relapsing, Recurrent, and Repeat Peritonitis}

- We recommend that timely catheter removal be considered for relapsing, recurrent, or repeat peritonitis episodes (1C).

The definitions of relapsing, recurrent, and repeat peritonitis are summarized in Table 7. Retrospective studies showed that relapsing, recurrent, and repeat peritonitis episodes are caused by different species of bacteria and probably represent distinct clinical entities $(166,345-347)$. When compared to non-relapsing episodes, relapsing ones are associated with a lower rate of cure, more ultrafiltration problems, and higher rate of technique failure $(166,348)$. Recurrent peritonitis episodes had a worse prognosis than relapsing ones $(166,345)$. A recent study suggested that bacterial DNA fragment levels in PD effluent are significantly higher 5 days before and on the date of completion of antibiotics amongst patients who subsequently develop relapsing or recurrent peritonitis (349). Another study suggests that effluent white cell count and leukocyte strip test at the time of stopping antibiotics may also predict relapse (350). However, further studies are needed to validate these results and confirm their clinical utility.

\section{Coagulase-Negative Staphylococcus}

- We suggest that coagulase-negative staphylococci generally be treated with IP cephalosporins or vancomycin, according to antimicrobial susceptibility, for a period of 2 weeks. (2C).

Coagulase-negative Staphylococcus peritonitis episodes, especially those caused by $S$. epidermidis, are mostly due to touch contamination. Many patients with $S$. epidermidis peritonitis have mild clinical symptoms and respond well to treatment as outpatients (351-353). In some centers, the prevalence of methicillin resistance is now very high $(354,355)$, and vancomycin may have to be considered as empirical therapy. Even for methicillin-sensitive strains, it is important to avoid inadequate IP antibiotic levels, which may lead to relapsing peritonitis. For this reason, continuous dosing of IP first-generation cephalosporins is preferable to intermittent dosing. Effective antibiotic treatment for 2 weeks is generally sufficient (351-354). The patient's exchange technique should be reviewed to prevent another episode.

This single copy is for your personal, non-commercial use only. 
TABLE 7

Terminology for Peritonitis

- Recurrent: An episode that occurs within 4 weeks of completion of therapy of a prior episode but with a different organism

- Relapsing: An episode that occurs within 4 weeks of completion of therapy of a prior episode with the same organism or one sterile episode

- Repeat: An episode that occurs more than 4 weeks after completion of therapy of a prior episode with the same organism

- Refractory: Failure of the effluent to clear after 5 days of appropriate antibiotics

- Catheter-related peritonitis: Peritonitis in conjunction with an exitsite or tunnel infection with the same organism or one site sterile

N.B. Relapsing episodes should not be counted as another episode during the calculation of peritonitis rates; recurrent and repeat episodes should be counted.

Relapsing coagulase-negative Staphylococcus peritonitis suggests colonization of the PD catheter with biofilm, and catheter removal should be considered. When the PD effluent becomes clear with antibiotic therapy, many of these patients could have simultaneous re-insertion of a new catheter as a single procedure under antibiotic coverage, and temporary hemodialysis could be avoided (204). In addition to conventional antibiotics, a retrospective study found that IP urokinase and oral rifampicin resulted in catheter salvage in $64 \%$ of cases with persisting asymptomatic infection following coagulasenegative Staphylococcus peritonitis (337), but the benefit of this approach needs to be confirmed by further studies.

\section{Enterococcus Species}

- We suggest that enterococcal peritonitis be treated for 3 weeks with IP vancomycin (2C).

- We suggest adding IP aminoglycoside for severe enterococcal peritonitis (2D).

- For peritonitis due to vancomycin-resistant Enterococcus (VRE), we suggest treatment for 3 weeks with IP ampicillin if the organism is susceptible or with alternative antibiotics (linezolid, quinupristin/dalfopristin, daptomycin or teicoplanin, based on antimicrobial susceptibilities) if the organism is ampicillin-resistant (2D).

Enterococci are normal flora of the gastrointestinal tract $(356,357)$. Intra-abdominal source must be considered. Other pathogenic organisms are isolated in about half of the cases of enterococcal peritonitis, and the coexistence of other organisms was associated with high rates of catheter removal, permanent hemodialysis transfer, and death $(356,357)$.

Enterococcal species are always resistant to cephalosporins. Identification of the exact species is important because resistance to penicillins and carbapenems is far more frequently observed in E. faecium than in E. faecalis (358). Although there may be clinical response to empirical therapy with firstgeneration cephalosporins (359), peritonitis episodes should be treated with IP vancomycin if the organism is susceptible. For patients with severe signs or symptoms, an aminoglycoside may be added for synergy. However, aminoglycosides should not be added to the same bag with penicillins because of chemical incompatibility (see Antibiotic Delivery and Stability). Although ampicillin has little in vitro activity when added to common PD solutions (331), clinical experience suggests clinical efficiency (356). For vancomycin-resistant enterococcus (VRE) causing peritonitis, if the bacterial isolate is ampicillin-susceptible, ampicillin remains the drug of choice. Otherwise, linezolid, quinupristin/dalfopristin, or daptomycin are valid options $(278,281,292,360-363)$. Given the clinical efficacy and profile of adverse effects, daptomycin is probably the first-line antibiotic of choice for peritonitis episodes caused by VRE (278,363-365). Bone marrow suppression usually occurs after 10 to 14 days of linezolid therapy, and prolonged therapy may also result in neurotoxicity. One previous study showed that removal of the PD catheter within 1 week of the onset of refractory enterococcal peritonitis was associated with a significant reduction in the risk of permanent hemodialysis transfer (356).

\section{Streptococcal Species}

- We suggest that streptococcal peritonitis be treated with appropriate antibiotics, such as IP ampicillin, for 2 weeks (2C).

Streptococci frequently originate from the mouth (175), although S. bovis typically comes from the colon (366). Peritonitis episodes caused by streptococci usually respond well to antibiotic treatment $(175,367)$, but viridans streptococcal peritonitis are more likely to be refractory (368). Cefazolin and vancomycin are often effective.

\section{Staphylococcus Aureus}

- We suggest that Staphylococcus aureus peritonitis be treated with effective antibiotics for 3 weeks (2C).

Peritonitis episodes caused by Staphylococcus aureus are often secondary to exit-site or tunnel infection, although touch contamination is also common. If the bacterial isolate is methicillin-sensitive, a first-generation cephalosporin is the drug of choice. Two retrospective studies found that the initial empiric antibiotic choice between vancomycin and cefazolin had similar clinical outcomes $(369,370)$. If the isolate is methicillinresistant, IP vancomycin is the drug of choice, but teicoplanin and daptomycin can be used as alternatives (371). One study showed that the use of adjuvant rifampicin for 5 to 7 days may reduce the risk for relapsing or repeat $S$. aureus peritonitis (369). However, rifampicin is a potent liver enzyme inducer and interaction with other concomitant medications may be problematic.

Observational data suggest that treatment with effective antibiotics for 3 weeks is needed $(369,370,372)$. Prolonged vancomycin therapy may predispose to the emergence of vancomycin-resistant $S$. aureus and should be avoided

This single copy is for your personal, non-commercial use only. For permission to reprint multiple copies or to order presentation-ready copies for distribution, contact Multimed Inc. at marketing@multi-med.com 
whenever possible. For patients with concomitant S. aureus exit-site or catheter tunnel infection, catheter removal should be considered.

\section{Corynebacterium Peritonitis}

- We suggest that corynebacterial peritonitis be treated with effective antibiotics for 3 weeks (2C).

Corynebacterium species belong to the natural flora of the skin. Infections due to Corynebacterium have been increasingly recognized over the past decades, largely due to improved recognition and microbiological techniques. In a retrospective study, Corynebacterium peritonitis often resulted in relapse or repeat episodes, catheter removal, permanent hemodialysis transfer, and death (373). Another retrospective study found that relapsing Corynebacterium peritonitis was common after a 2-week course of antibiotic treatment, but relapsing episodes can usually be cured with a 3-week course of IP vancomycin (374). For refractory Corynebacterium peritonitis, observational data suggest that catheter removal within 1 week after the onset of peritonitis significantly reduces the risk of permanent hemodialysis transfer (373). For patients with concomitant exit-site or catheter tunnel infection caused by Corynebacterium, early catheter removal should be considered.

\section{Pseudomonas Peritonitis}

- We suggest that Pseudomonas peritonitis be treated with 2 antibiotics with different mechanisms of action and to which the organism is sensitive (e.g. IP gentamicin or oral ciprofloxacin with IP ceftazidime or cefepime) for 3 weeks (2C).

- We suggest that Pseudomonas peritonitis with concomitant exit-site and tunnel infection be treated with catheter removal (2D).

Pseudomonas peritonitis is generally severe and often associated with infection of the catheter. Pseudomonas aeruginosa is the most common species. Retrospective studies have shown that Pseudomonas peritonitis is associated with greater frequencies of hospitalization, high rates of catheter removal and permanent hemodialysis transfer (375-377). The use of 2 anti-pseudomonal antibiotics is associated with better outcomes (377). Carbapenems, such as imipenem, meropenem, and doripenem are valid alternatives, especially if the bacterial isolate is resistant to cephalosporin and anti-pseudomonal penicillins. If fluoroquinolone is used as part of the regimen, ciprofloxacin should be used, while moxifloxacin has very little anti-pseudomonal activity. If concomitant catheter infection is present, catheter removal is often needed.

\section{Other Gram-Negative Bacteria}

- We suggest that non-Pseudomonas gram-negative peritonitis be treated with effective antibiotics for at least 3 weeks (2C).
If single gram-negative organisms are isolated, the antibiotic should be chosen according to sensitivity, safety, and convenience. It is important to note that bacteria in biofilm are considerably less sensitive than that indicated by laboratory testing (378), which may account for the high percentage of treatment failures, even though the organism appears to be sensitive to the antibiotic in vitro $(379,380)$. Retrospective studies have shown that gram-negative peritonitis had higher risks of catheter loss and death than gram-positive episodes (379-384). In one study, recent antibiotic therapy was the major risk factor of antibiotic resistance, while ESI, and possibly recent antibiotic therapy, were associated with poor therapeutic response (382). The SPICE organisms (Serratia, Pseudomonas, indole-positive organisms such as Proteus and Providentia, Citrobacter, and Enterobacter) have amp-C beta-lactamases, which inactivate cephalosporins, and have a high risk of relapse. Although single antibiotic therapy is often effective, 1 retrospective study suggested that treatment with 2 antibiotics may reduce the risk of relapse and recurrence (382).

In recent years, there has been widespread emergence of 2 antibiotic resistance mechanisms: extended-spectrum beta-lactamases (ESBLs) $(385,386)$ and carbapenem-resistant Enterobacteriaceae (CRE) $(385,387)$; the latter are also called Klebsiella pneumoniae carbapenemase (KPC)-producing bacteria when the carbapenem resistance is mediated by beta-lactamases. Extended-spectrum beta-lactamases are resistant to all cephalosporins but usually susceptible to carbapenems. Carbapenem-resistant Enterobacteriaceae/ KPC-producing bacteria are usually resistant to all classes of beta-lactams, usually resistant to fluoroquinolones, variably susceptible to aminoglycosides, but usually susceptible to polymyxin and colistin.

The isolation of a Stenotrophomonas species, while infrequent, requires special attention, as it is sensitive to only a few antimicrobial agents $(388,389)$. Recent treatment with carbapenems, fluoroquinolones, or third- or fourth-generation cephalosporins usually precedes Stenotrophomonas infections. Based on limited observational data, therapy with 2 antibiotics for 3 to 4 weeks is recommended $(388,389)$. If the isolate is sensitive to trimethoprim/sulfamethoxazole, this agent should be included in the regimen. Tigecycline, polymyxin B, and colistin are other possible alternatives.

\section{Polymicrobial Peritonitis}

- If multiple enteric organisms (multiple gram-negative or mixed gram-negative/gram-positive organisms) are grown from PD effluent, we suggest that surgical evaluation be obtained immediately when there is no prompt clinical response (1C) and that the patient be treated with metronidazole in conjunction with IP vancomycin and either IP aminoglycoside or IP ceftazidime for a minimum period of 3 weeks (2C).

- If multiple gram-positive organisms are grown from PD effluent, we suggest that patients be treated with effective antibiotics for 3 weeks (2C).

This single copy is for your personal, non-commercial use only. 
When multiple enteric organisms are grown from the PD effluent, there is a possibility of intra-abdominal pathology. Presentation with hypotension, sepsis, lactic acidosis, or elevated dialysis effluent amylase level should also raise the possibility of abdominal catastrophe $(390,391)$. When a surgical cause of peritonitis is suspected, the antibiotics of choice are metronidazole plus vancomycin, in combination with ceftazidime or an aminoglycoside. Monotherapy with a carbapenem or piperacillin/tazobactam may also be considered. Assessment by a surgeon is needed. Computed tomographic (CT) scan may help to identify the pathology, but a normal CT scan does not eliminate that possibility. If laparotomy is needed, the PD catheter is usually removed and antibiotics are continued via IV route.

In contrast, polymicrobial peritonitis due to multiple grampositive organisms often has a favorable prognosis $(392,393)$. Their clinical behavior is similar to peritonitis episodes caused by single gram-positive organisms and the etiology may well be touch contamination. Antibiotic therapy is often effective without catheter removal (392).

\section{Culture-Negative Peritonitis}

- We suggest that negative effluent cultures on day 3 warrant a repeat dialysis effluent WBC count with differential (2D).

- If the culture-negative peritonitis is resolving at day 3, we suggest discontinuing aminoglycoside therapy and continuing treatment with gram-positive coverage (e.g. first-generation cephalosporin or vancomycin) for 2 weeks (2C).

- If the culture-negative peritonitis is not resolving at day 3 , we suggest special culture techniques be considered for isolation of unusual organisms (2C).

Recent antibiotic usage and technical problems of culturing the specimen are the major reasons for negative effluent cultures (394-396). If PD effluent yields no growth after 3 days, a repeat WBC count with differential should be obtained. If the repeat cell count indicates that the infection has not resolved, special culture techniques may be considered for the isolation of unusual organisms (e.g. mycobacteria, nocardia, legionella, filamentous fungus, and other fastidious bacteria). This would require close liaison with the microbiology laboratory.

Many culture-negative peritonitis episodes are probably caused by gram-positive organisms. If the patient improves clinically, initial therapy should be continued (394-396). Duration of therapy should be 2 weeks if the effluent clears promptly. In contrast, if there is suboptimal response after 5 days of empirical antibiotics, catheter removal should be strongly considered.

\section{Fungal Peritonitis}

- We recommend immediate catheter removal when fungi are identified in PD effluent (1C).

- We suggest that treatment with an appropriate anti-fungal agent be continued for at least 2 weeks after catheter removal (2C).

Fungal peritonitis is a serious complication with high rates of hospitalization, catheter removal, transfer to hemodialysis, and death (397-400). Initial therapy is traditionally a combination of amphotericin B and flucytosine. However, IP amphotericin causes chemical peritonitis and pain, while IV administration has poor peritoneal bioavailability. In addition, flucytosine is not widely available. If flucytosine is used, regular monitoring of serum concentration is necessary to avoid bone marrow toxicity. Peak serum flucytosine levels, measured $1-2$ hours after an oral dose, should be $25-50 \mathrm{mcg} /$ $\mathrm{mL}(401,402)$.

Other agents of choice include fluconazole, an echinocandin (e.g. caspofungin, micafungin, or anidulafungin), posaconazole, and voriconazole. Although fluconazole is commonly used, the prevalence of azole resistance is increasing (403). Fluconazole only has activity against Candida species and Cryptococcus. Echinocandins have been advocated for the treatment of fungal peritonitis caused by Aspergillus species and non-albicans Candida species, or in patients intolerant to other antifungal therapies $(297,298,398)$. Caspofungin has been used successfully as monotherapy or in combination with amphotericin $(297,298)$. Posaconazole and voriconazole have been successfully used for the treatment of peritonitis caused by filamentous fungi $(287,300,301)$.

Irrespective of the choice of anti-fungal agent, observational studies suggest that prompt catheter removal probably improves outcome and reduces mortality $(300,301,397,398,400,404)$. Anti-fungal agents should be continued after catheter removal for at least 2 weeks. A recent study suggested that around onethird of patients could return to PD (399).

\section{Tuberculous Peritonitis}

Although classical symptoms of fever, abdominal pain, and cloudy effluent may occur with tuberculous peritonitis, the diagnosis should be considered in any patient with refractory or relapsing peritonitis with negative bacterial cultures. Similar to bacterial peritonitis, most cases of tuberculous peritonitis have PMN in the dialysis effluent at initial presentation, but lymphocytosis in the dialysis effluent usually becomes obvious later. Ziehl-Neelsen stain examination of the PD effluent is often unrevealing, and conventional culture technique (e.g. Löwenstein-Jensen agar) is slow and not sufficiently sensitive. The time to develop a positive culture is considerably decreased in fluid medium (e.g. Septi-Chek, BACTEC; Becton Dickinson, NJ, USA). Overall diagnostic yield could be improved by centrifuging a large volume of effluent ( 50 to $100 \mathrm{~mL}$ ), followed by culturing the sediment in both solid and fluid media. Alternatively, mycobacterial DNA PCR can be performed on dialysis effluent, although false-positives are not uncommon (405). Laparoscopy with biopsy of the peritoneum or omentum has also been advocated for rapid diagnosis if the index of suspicion is high (406). 
The treatment protocol should be based on general protocols for treatment of tuberculosis but is often started with 4 drugs: rifampicin, isoniazid, pyrazinamide, and ofloxacin. A previous study showed that rifampicin levels in PD effluent are often low (407). Intraperitoneal rifampicin treatment has been advocated but is not available in many countries. In general, pyrazinamide and ofloxacin could be stopped after 2 months, while rifampicin and isoniazid should be continued for a total of 12 to 18 months (407-413). Pyridoxine (50 to $100 \mathrm{mg} /$ day) should be given to avoid isoniazid-induced neurotoxicity. On the other hand, long-term use of pyridoxine at a higher dose (e.g. $200 \mathrm{mg}$ daily) is in itself associated with neuropathy and should be avoided. Streptomycin, even in reduced doses, may cause ototoxicity after prolonged use and should be avoided. Ethambutol is associated with a high risk of optic neuritis in dialysis patients and must be used with appropriate dosage reduction. Previous reports suggest a dose of $15 \mathrm{mg} / \mathrm{kg}$ every 48 hours or thrice weekly for up to 2 months (414). The optimal treatment for drug-resistant tuberculous peritonitis remains unknown.

Many patients respond to anti-tuberculous therapy without catheter removal $(407-413,415)$. However, it is important to differentiate patients with miliary tuberculosis, whose peritonitis is part of the disseminated disease, from those with isolated tuberculous peritonitis without extraperitoneal infection, because the duration of anti-tuberculous therapy is different.

\section{Non-Tuberculous Mycobacterial Peritonitis}

Data on peritonitis caused by non-tuberculous mycobacteria are limited but may be increasing $(21,416-422)$. It is not uncommon for non-tuberculous mycobacteria to be misidentified as gram-positive diphtheroids. Over half of the isolates are rapidly growing species, such as $M$. fortuitum and $M$. chelonae (420), and often become positive on routine bacteriologic cultures in 3 to 5 days. It has been postulated that extensive use of topical gentamicin ointment for exit-site infection may predispose patients to non-tuberculous mycobacterial infection of the exit site (144). The treatment regimen for nontuberculous mycobacterial peritonitis is not well established and requires individualized protocols based on susceptibility testing. Catheter removal is usually necessary, and experience with non-removal is limited (420-422). The type and duration of antibiotic therapy are variable, and the optimal treatment regimen is poorly defined and depends on species and drug susceptibilities (416-422).

\section{Catheter Removal and Re-Insertion}

- We recommend that PD catheters be removed for refractory, relapsing, or fungal peritonitis unless there are clinical contraindications (1C).

- We suggest that it is appropriate to consider return to PD for many patients who have had their catheter removed for refractory, relapsing, or fungal peritonitis (2C).
- We suggest that if re-insertion of a new catheter is attempted after a PD catheter is removed for refractory, relapsing, or fungal peritonitis, it be performed at least 2 weeks after catheter removal and complete resolution of peritoneal symptoms (2D).

Indications for catheter removal are summarized in Table 8. For refractory peritonitis and fungal peritonitis, simultaneous re-insertion of a new PD catheter is not recommended, and patients should be put on temporary hemodialysis. Observational studies suggest that effective antibiotics should be continued for at least 2 weeks after catheter removal for refractory peritonitis $(423,424)$.

After severe episodes of peritonitis, around $50 \%$ of patients could potentially return to PD (423-425). An ANZDATA Registry study demonstrated that return to PD after catheter removal and temporary hemodialysis for peritonitis was not associated with inferior patient-level clinical outcomes when compared with other patients who either never required hemodialysis transfer for peritonitis or who had permanent hemodialysis transfer for peritonitis (426). Furthermore, subsequent peritonitis-free, technique and patient survival following return to PD were not associated with organism type or duration of time from hemodialysis transfer to PD restart (426). There are few data on the optimal duration between catheter removal for peritonitis and re-insertion of a new catheter. Observational studies suggest a minimum period of 2 to 3 weeks (423-425), although some would recommend later re-insertion in cases of fungal peritonitis $(397,398)$. Re-insertion of a new catheter should be done by laparoscopic or mini-laparotomy approach so that adhesion can be directly visualized. Ultrafiltration problems are common after return to PD $(423,424)$. A small proportion of patients with PD-related peritonitis develop recurrent intra-abdominal collection that requires percutaneous drainage after catheter removal (427). The chance of a successful return to PD is very low in this group of patients, and direct conversion to long-term hemodialysis should be considered (427).

\section{FUTURE RESEARCH}

There are some new antibiotics that, to the best of our knowledge, have not been tried for the treatment of PD-related peritonitis. For example, ceftaroline has good coverage of

TABLE 8

Indications for Catheter Removal

- Refractory peritonitis

- Relapsing peritonitis

- Refractory exit-site and tunnel infection

- Fungal peritonitis

- Catheter removal may also be considered for

- repeat peritonitis

- mycobacterial peritonitis

- multiple enteric organisms

This single copy is for your personal, non-commercial use only. For permission to reprint multiple copies or to order presentation-ready copies for distribution, contact Multimed Inc. at marketing@multi-med.com 
gram-negative bacteria and is also active against MRSA and methicillin-resistant coagulase-negative staphylococci. The pharmacokinetic data of many new antibiotics, administered either systemically or IP, are much needed and some are in the pipeline (428). Many data on antibiotic stability in PD solutions are old and need to be repeated in new PD solutions. Pharmacodynamic investigations specific to PD-related peritonitis are scarce. The impact of antibiotic resistance also requires further study.

MALDI-TOF mass spectrometry has recently been used in academic facilities to identify microorganisms in biologic fluids. This technique may shorten the time to species identification and also help to identify rare or unknown pathogens. The application of MALDI-TOF mass spectrometry and other novel techniques to the diagnosis of PD peritonitis deserves further study.

Clinical trials are also required in order to assess the efficacy and safety of various treatment regimens, especially for the treatment of peritonitis in APD. Outcomes to be examined should include not only resolution without catheter removal, but also the duration of peritoneal inflammation, relapsing and repeat episodes, as well as the change in peritoneal solute transport status after resolution of peritonitis. Further studies are also needed on primary and secondary prevention of peritonitis. The efficacy of treating many "modifiable" risk factors has not been formally tested. Research on the biology and management of catheter biofilm is also needed. Finally, whilst PD training is widely acknowledged as crucial to achieving good clinical outcomes in PD, high-level evidence guiding how, where, when, and by whom PD training should be performed is lacking. Research in this area should explicitly detail the training curriculum and approach (rather than vaguely alluding to adult-learning principles) to permit generalizability of study findings.

\section{DISCLOSURES}

CCS receives research grant and consultancy amounts from Baxter Healthcare. AF received consultant and speaker fees from Baxter Healthcare. EG is a member of the advisory board for Baxter Healthcare and $\mathrm{Nx}$ Stage and received honoraria from Baxter Healthcare, Nx Stage, Shire, Alexion and Sanofi. DJ has previously received consultancy fees, research funding, travel sponsorship and research funding from Baxter Healthcare and Fresenius Medical Care. He has also received travel sponsorship from Amgen. The others declare no conflict of interests.

\section{REFERENCES}

1. Ghali JR, Bannister KM, Brown FG, Rosman JB, Wiggins KJ, Johnson DW, McDonald SP. Microbiology and outcomes of peritonitis in Australian peritoneal dialysis patients. Perit Dial Int 2011; 31:651-62.

2. Pérez Fontan M, Rodríguez-Carmona A, García-Naveiro R, Rosales M, Villaverde $P$, Valdés F. Peritonitis-related mortality in patients undergoing chronic peritoneal dialysis. Perit Dial Int 2005; 25:274-84.

3. Davenport A. Peritonitis remains the major clinical complication of peritoneal dialysis: the London, UK, peritonitis audit 2002-2003. Perit Dial Int 2009; 29:297-302.

4. Szeto CC, Wong TY, Chow KM, Leung CB, Li PK. Are peritoneal dialysis patients with and without residual renal function equivalent for survival study? Insight from a retrospective review of the cause of death. Nephrol Dial Transplant 2003; 18:977-82.

5. Brown MC, Simpson K, Kerssens JJ, Mactier RA. Peritoneal dialysisassociated peritonitis rates and outcomes in a national cohort are not improving in the post-millennium (2000-2007). Perit Dial Int 2011; 31:639-50.

6. Boudville N, Kemp A, Clayton P, Lim W, Badve SV, Hawley CM, et al. Recent peritonitis associates with mortality among patients treated with peritoneal dialysis. J Am Soc Nephrol 2012; 23:1398-405.

7. Hsieh YP, Chang CC, Wen YK, Chiu PF, Yang Y. Predictors of peritonitis and the impact of peritonitis on clinical outcomes of continuous ambulatory peritoneal dialysis patients in Taiwan-10 years' experience in a single center. Perit Dial Int 2014; 34:85-94.

8. Hsieh YP, Chang CC, Wang SC, Wen YK, Chiu PF, Yang Y. Predictors for and impact of high peritonitis rate in Taiwanese continuous ambulatory peritoneal dialysis patients. Int Urol Nephrol 2015; 47:183-9.

9. Keane WF, Everett ED, Golper TA, Gokal R, Halstenson C, Kawaguchi Y, et al. Peritoneal dialysis-related peritonitis treatment recommendations: 1993 update. The Ad Hoc Advisory Committee on Peritonitis Management. International Society for Peritoneal Dialysis. Perit Dial Int 1993;13:14-28.

10. Keane WF, Alexander SR, Bailie GR, Boeschoten E, Gokal R, Golper TA, et al. Peritoneal dialysis-related peritonitis treatment recommendations: 1996 update. Perit Dial Int 1996; 16:557-73.

11. Keane WF, Bailie GR, Boeschoten E, Gokal R, Golper TA, Holmes CJ, et al. Adult peritoneal dialysis-related peritonitis treatment recommendations: 2000 update. Perit Dial Int 2000; 20:396-411.

12. Piraino B, Bailie GR, Bernardini J, Boeschoten E, Gupta A, Holmes C, et al.; ISPD Ad Hoc Advisory Committee. Peritoneal dialysis-related infections recommendations: 2005 update. Perit Dial Int 2005; 25:107-31.

13. Li PK, Szeto CC, Piraino B, Bernardini J, Figueiredo AE, Gupta A, et al. Peritoneal dialysis-related infections recommendations: 2010 update. Perit Dial Int 2010; 30:393-423.

14. Piraino B, Bernardini J, Brown E, Figueiredo A, Johnson DW, Lye WC, et al. ISPD position statement on reducing the risks of peritoneal dialysisrelated infections. Perit Dial Int 2011; 31:614-30.

15. Atkins $D$, Best $D$, Briss PA, Eccles $M$, Falck-Ytter Y, Flottorp S, et al.; GRADE Working Group. Grading quality of evidence and strength of recommendations. BMJ 2004; 328:1490.

16. Warady BA, Bakkaloglu S, Newland J, Cantwell M, Verrina E, Neu A, et al. Consensus guidelines for the prevention and treatment of catheterrelated infections and peritonitis in pediatric patients receiving peritoneal dialysis: 2012 update. Perit Dial Int 2012; 32(Suppl 2):S32-86.

17. Borg D, Shetty A, Williams D, Faber MD. Fivefold reduction in peritonitis using a multifaceted continuous quality initiative program. Adv Perit Dial 2003; 19:202-5.

18. Diaz-Buxo JA, Wick GS, Pesich AA. Using CQI techniques for managing infections in PD patients. Nephrol News Issues 1998; 12:22-4.

19. Cho Y, Johnson DW. Peritoneal dialysis-related peritonitis: towards improving evidence, practices, and outcomes. Am J Kidney Dis 2014; 64:278-89.

20. Piraino B. Today's approaches to prevent peritonitis. Contrib Nephrol 2012; $178: 246-50$.

21. Kunin M, Knecht A, Holtzman EJ. Mycobacterium chelonae peritonitis in peritoneal dialysis. Literature review. Eur J Clin Microbiol Infect Dis 2014; 33:1267-71.

22. Kavanagh D, Prescott GJ, Mactier RA. Peritoneal dialysis-associated peritonitis in Scotland (1999-2002). Nephrol Dial Transplant 2004; 19:2584-91.

23. Kopriva-Altfahrt G, König P, Mündle M, Prischl F, Roob JM, Wiesholzer M, et al. Exit-site care in Austrian peritoneal dialysis centers-a nationwide survey. Perit Dial Int 2009; 29:330-9.

24. Han SH, Lee SC, Ahn SV, Lee JE, Choi HY, Kim BS, et al. Improving outcome ofCAPD: twenty-five years' experience in a single Korean center. Perit Dial Int 2007; 27:432-40.

25. Moraes TP, Pecoits-Filho R, Ribeiro SC, Rigo M, Silva MM, Teixeira PS, et al. Peritoneal dialysis in Brazil: twenty-five years of experience in a single center. Perit Dial Int 2009; 29:492-8.

This single copy is for your personal, non-commercial use only. For permission to reprint multiple copies or to order presentation-ready copies for distribution, contact Multimed Inc. at marketing@multi-med.com 
26. Rocha A, Rodrigues A, Teixeira L, Carvalho MJ, Mendonca D, Cabrita A. Temporal trends in peritonitis rates, microbiology and outcomes: the major clinical complication of peritoneal dialysis. Blood Purif 2012; 33:284-91.

27. Fang W, Ni Z, Qian J. Key factors for a high-quality peritoneal dialysis program -the role of the PD team and continuous quality improvement. Perit Dial Int 2014; 34(Suppl 2):S35-42.

28. Nishina M, Yanagi H, Kakuta T, Endoh M, Fukagawa M, Takagi A. A 10-year retrospective cohort study on the risk factors for peritoneal dialysisrelated peritonitis: a single-center study at Tokai University Hospital. Clin Exp Nephrol 2014; 18:649-54.

29. Schaefer F, Kandert M, Feneberg R. Methodological issues in assessing the incidence of peritoneal dialysis-associated peritonitis in children. Perit Dial Int 2002; 22:234-8.

30. Pajek J, Hutchison AJ, Bhutani S, Brenchley PE, Hurst H, Perme MP, et al. Outcomes of peritoneal dialysis patients and switching to hemodialysis: a competing risks analysis. Perit Dial Int 2014; 34:289-98.

31. van Diepen AT, Tomlinson GA, Jassal SV. The association between exit site infection and subsequent peritonitis among peritoneal dialysis patients. Clin J Am Soc Nephrol 2012; 7:1266-71.

32. Figueiredo A, Goh B, Jenkins S, Johnson DW, Mactier R, Ramalakshmi S, et al. Clinical practice guidelines for peritoneal access. Perit Dial Int 2010; 30:424-9.

33. Wikdahl AM, Engman U, Stegmayr BG, Sorenssen JG. One-dose cefuroxime IV and IP reduces microbial growth in PD patients after catheter insertion. Nephrol Dial Transplant 1997; 12:157-60.

34. Bennet-Jones DN, Martin JB, Barratt AJ, Duffy TJ, Naish PF, Aber GM. Prophylactic gentamicin in the prevention of early exit-site infections and peritonitis in CAPD. Adv Perit Dial 1988; 4:147-50.

35. Lye WC, Lee EJ, Tan CC. Prophylactic antibiotics in the insertion of Tenckhoff catheters. Scand J Urol Nephrol 1992; 26:177-80.

36. Gadallah MF, Ramdeen G, Mignone J, Patel D, Mitchell L, Tatro S. Role of preoperative antibiotic prophylaxis in preventing postoperative peritonitis in newly placed peritoneal dialysis catheters. Am J Kidney Dis 2000 ; 36:1014-9.

37. Strippoli GFM, Tong A, Johnson D, Schena FP, Craig JC. Antimicrobial agents to prevent peritonitis in peritoneal dialysis: a systematic review of randomized controlled trials. Am J Kidney Dis 2004; 44:591-603.

38. Gadallah MF, Pervez A, el-Shahawy MA, Sorrells D, Zibari G, McDonald J, et al. Peritoneoscopic versus surgical placement of peritoneal dialysis catheters: a prospective randomized study on outcome. Am J Kidney Dis 1999; 33:118-22.

39. Tsimoyiannis EC, Siakas P, Glantzounis G, Toli C, Sferopoulos G, Pappas $M$, et al. Laparoscopic placement of the Tenckhoff catheter for peritoneal dialysis. Surg Laparosc Endosc Percutan Tech 2000; 10:218-21.

40. Wright MJ, Bel'eed K, Johnson BF, Eadington DW, Sellars L, Farr MJ. Randomized prospective comparison of laparoscopic and open peritoneal dialysis catheter insertion. Perit Dial Int 1999; 19:372-5.

41. Jwo SC, Chen KS, Lee CC, Chen HY. Prospective randomized study for comparison of open surgery with laparoscopic-assisted placement of Tenckhoff peritoneal dialysis catheter-a single center experience and literature review. J Surg Res 2010; 159:489-96.

42. Strippoli GF, Tong A, Johnson D, Schena FP, Craig JC. Catheter-related interventions to prevent peritonitis in peritoneal dialysis: a systematic review of randomized, controlled trials. J Am Soc Nephrol 2004; 15:2735-46.

43. Ejlersen E, Steven K, Lokkegaard H. Paramedian versus midline incision for the insertion of permanent peritoneal dialysis catheters. A randomized clinical trial. Scand J Urol Nephrol 1990; 24:151-4.

44. Rubin J, Didlake R, Raju S, Hsu H. A prospective randomized evaluation of chronic peritoneal catheters. Insertion site and intraperitoneal segment. ASAIO Trans 1990; 36:M497-500.

45. Moncrief JW, Popovich RP, Dasgupta M, Costerton JW, Simmons E, Moncrief B. Reduction in peritonitis incidence in continuous ambulatory peritoneal dialysis with a new catheter and implantation technique. Perit Dial Int 1993; 13(Suppl 2):S329-31.

46. Park MS, Yim AS, Chung SH, Lee EY, Cha MK, Kim JH, et al. Effect of prolonged subcutaneous implantation of peritoneal catheter on peritonitis rate during CAPD: a prospective randomized study. Blood Purif 1998; 16:171-8.

47. Danielsson A, Blohme L, Tranaeus A, Hylander B. A prospective randomized study of the effect of a subcutaneously 'buried' peritoneal dialysis catheter technique versus standard technique on the incidence of peritonitis and exit-site infection. Perit Dial Int 2002; 22:211-9.

48. Twardowski ZJ. Presternal peritoneal catheter. Adv Ren Replace Ther 2002; 9:125-32.

49. Akyol AM, Porteous C, Brown MW. A comparison of two types of catheters for continuous ambulatory peritoneal dialysis (CAPD). Perit Dial Int 1990; $10: 63-6$.

50. Eklund BH, Honkanen EO, Kala AR, Kyllonen LE. Catheter configuration and outcome in patients on continuous ambulatory peritoneal dialysis: a prospective comparison of two catheters. Perit Dial Int 1994; 14:70-4.

51. Eklund BH, Honkanen EO, Kala AR, Kyllonen LE. Peritoneal dialysis access: prospective randomized comparison of the Swan neck and Tenckhoff catheters. Perit Dial Int 1995; 15:353-6.

52. Lye WC, Kour NW, van der Straaten JC, Leong S0, Lee EJ. A prospective randomized comparison of the swan neck, coiled, and straight Tenckhoff catheters in patients on CAPD. Perit Dial Int 1996; 16(Suppl 1):S333-5.

53. Nielsen PK, Hemmingsen C, Friis SU, Ladefoged J, Olgaard K. Comparison of straight and curled Tenckhoff peritoneal dialysis catheters implanted by percutaneous technique: a prospective randomized study. Perit Dial Int 1995; 15:18-21.

54. Scott PD, Bakran A, Pearson R, Riad H, Parrott N, Johnson RW, Gokal R. Peritoneal dialysis access. Prospective randomized trial of 3 different peritoneal catheters - preliminary report. Perit Dial Int 1994; 14:289-90.

55. Johnson DW, Wong J, Wiggins KJ, Kirwan R, Griffin A, Preston J, et al. A randomized controlled trial of coiled versus straight swan-neck Tenckhoff catheters in peritoneal dialysis patients. Am J Kidney Dis 2006; 48:812-21.

56. Hagen SM, Lafranca JA, Ijzermans JN, Dor FJ. A systematic review and meta-analysis of the influence of peritoneal dialysis catheter type on complication rate and catheter survival. Kidney Int 2014; 85:920-32.

57. Xie JY, Chen N, Ren H, Huang XM, Zhu P. Prospective studies on applications of a two-cuff swan neck catheter and a Tenckhoff catheter to Chinese CAPD patients. Clin Nephrol 2009; 72:373-9.

58. Li CL, Cui TG, Gan HB, Cheung K, Lio WI, Kuok UI. A randomized trial comparing conventional swan-neck straight-tip catheters to straight-tip catheters with an artificial subcutaneous swan neck. Perit Dial Int 2009; 29:278-84.

59. USRDS. US Renal Data System Annual Data Report IV. Catheter-related factors and peritonitis risk in CAPD patients. Am J Kidney Dis 1992; 20(Suppl 2):48-54.

60. Honda M, Iitaka K, Kawaguchi H, Hoshii S, Akashi S, Kohsaka T, et al. The Japanese National Registry data on pediatric CAPD patients: a ten-year experience. A report of the Study Group of Pediatric PD Conference. Perit Dial Int 1996; 16:269-75.

61. Warady BA, Sullivan EK, Alexander SR. Lessons from the peritoneal dialysis patient database: a report of the North American Pediatric Renal Transplant Cooperative Study. Kidney Int 1996; 53:S68-71.

62. Nessim SJ, Bargman JM, Jassal SV. Relationship between double-cuff versus single-cuff peritoneal dialysis catheters and risk of peritonitis. Nephrol Dial Transplant 2010; 25:2310-14.

63. Eklund B, Honkanen E, Kyllonen L, Salmella K, Kala AR. Peritoneal dialysis access: prospective randomized comparison of single-cuffand double-cuff straight Tenckhoff catheters. Nephrol Dial Transplant 1997; 12:2664-6.

64. Lo WK, Lui SL, Li FK, Choy BY, Lam MF, Tse KC, et al. A prospective randomized study on three different peritoneal dialysis catheters. Perit Dial Int 2003; 23(Suppl 2):S127-31.

65. Burkart JM, Hylander B, Durnell-Figel T, Roberts D. Comparison of peritonitis rates during long-term use of standard spike versus Ultraset in continuous ambulatory peritoneal dialysis (CAPD). Perit Dial Int 1990; 10:41-3.

66. Maiorca R, Cantaluppi A, Cancarini GC, Scalamogna A, Broccoli R, Graziani $G$, et al. Prospective controlled trial of a Y-connector and disinfectant to prevent peritonitis in continuous ambulatory peritoneal dialysis. Lancet 1983; 2:642-4.

67. Scalamogna A, De Vecchi A, Castelnovo C, Guerra L, Ponticelli C. Long-term This single copy is for your personal, non-commercial use only.

For permission to reprint multiple copies or to order presentation-ready

copies for distribution, contact Multimed Inc. at marketing@multi-med.com 
incidence of peritonitis in CAPD patients treated by the Y-set technique: experience in a single center. Nephron 1990; 55:24-7.

68. Harris DC, Yuill EJ, Byth K, Chapman JR, Hunt C. Twin- versus single-bag disconnect systems: infection rates and cost of continuous ambulatory peritoneal dialysis. J Am Soc Nephrol 1996; 7:2392-8.

69. Kiernan L, Kliger A, Gorban-Brennan N, Juergensen P, Tesin D, Vonesh E, et al. Comparison of continuous ambulatory peritoneal dialysis-related infections with different 'Y-tubing' exchange systems. J Am Soc Nephrol $1995 ; 5: 1835-8$.

70. Li PK, Szeto CC, Chau KF, Fung KS, Leung CB, Li CS, et al. Comparison of double-bag and $\mathrm{Y}$-set disconnect systems in continuous ambulatory peritoneal dialysis: a randomized prospective multicenter study. Am J Kidney Dis 1999; 33:535-40.

71. Monteon F, Correa-Rotter R, Paniagua R, Amato D, Hurtado ME, Medina $\mathrm{JL}$, et al. Prevention of peritonitis with disconnect systems in CAPD: a randomized controlled trial. The Mexican Nephrology Collaborative Study Group. Kidney Int 1998; 54:2123-8.

72. Cheng IK, Chan CY, Cheng SW, Poon JF, Ji YL, Lo WK, et al. A randomized prospective study of the cost-effectiveness of the conventional spike, 0 -set, and UVXD techniques in continuous ambulatory peritoneal dialysis. Perit Dial Int 1994; 14:255-60.

73. Canadian CAPD Clinical Trials Group. Peritonitis in continuous ambulatory peritoneal dialysis (CAPD): a multi-centre randomized clinical trial comparing the Y-connector disinfectant system to standard systems. Perit Dial Int 1989; 9:159-63.

74. Dryden MS, McCann M, Wing AJ, Phillips I. Controlled trial of a Y-set dialysis delivery system to prevent peritonitis in patients receiving continuous ambulatory peritoneal dialysis. J Hosp Infect 1992; 20:185-92.

75. Li PK, Chan TH, So WY, Wang AY, Leung CB, Lai KN. Comparisons of Y-set disconnect system (Ultraset) versus conventional spike system in uremic patients on CAPD: outcome and cost analysis. Perit Dial Int 1996; 16(Suppl 1):S368-70.

76. Owen JE, Walker RG, Lemon J, Brett L, Mitrou D, Becker GJ. Randomized study of peritonitis with conventional versus 0 -set techniques in continuous ambulatory peritoneal dialysis. Perit Dial Int 1992; 12:216-20.

77. Viglino G, Colombo A, Scalamogna A, Cavalli PL, Guerra L, Renzetti G, et al. Prospected randomized study of two $Y$ devices in continuous ambulatory peritoneal dialysis (CAPD). Perit Dial Int 1989; 9:165-8.

78. Viglino G, Colombo A, Cantu P, Camerini C, Catizone L, Bonello F, et al. In vitro and in vivo efficacy of a new connector device for continuous ambulatory peritoneal dialysis. Perit Dial Int 1993; 13(Suppl 2):S148-51.

79. Rottembourg J, Brouard R, Issad B, Allouache M, Jacobs C. Prospective randomized study about Y-connectors in CAPD patients. Adv Perit Dial $1987 ; 3: 107-13$.

80. Lindholm T, Simonsen 0, Krutzen L. Evaluation of a new take-off system (Ultraset) versus conventional spike system in uremic patients on CAPD: outcome and cost-analysis. Adv Perit Dial 1988; 4:262-5.

81. Daly C, Cody JD, Khan I, Rabindranath KS, Vale L, Wallace SA. Double bag or Y-set versus standard transfer systems for continuous ambulatory peritoneal dialysis in end-stage kidney disease. Cochrane Database Syst Rev 2014; 8:CD003078.

82. Daly CD, Campbell MK, MacLeod AM, Cody DJ, Vale LD, Grant AM, et al. Do the $Y$-set and double-bag systems reduce the incidence of CAPD peritonitis? A systematic review of randomized controlled trials. Nephrol Dial Transplant 2001; 16:341-7.

83. Piraino B, Sheth H. Peritonitis-does peritoneal dialysis modality make a difference? Blood Purification 2010; 29:145-9.

84. Mehrotra R, Chiu YW, Kalantar-Zadeh K, Vonesh E. The outcomes of continuous ambulatory and automated peritoneal dialysis are similar. Kidney Int 2009; 76:97-107.

85. Rabindranath KS, Adams J, Ali TZ, MacLeod AM, Vale L, Cody J, et al. Continuous ambulatory peritoneal dialysis versus automated peritoneal dialysis for end-stage renal disease. Cochrane Database Syst Rev 2007; 2:CD006515.

86. Rodriguez-Carmona A, Perez Fontan M, Garcia Falcon T, Fernandez Rivera C, Valdes F. A comparative analysis on the incidence of peritonitis and exit-site infection in CAPD and automated peritoneal dialysis. Perit Dial Int 1999; 19:253-8.
87. Bieber SD, Burkart J, Golper TA, Teitelbaum I, Mehrotra R. Comparative outcomes between continuous ambulatory and automated peritoneal dialysis: a narrative review. Am J Kidney Dis 2014; 63:1027-37.

88. Akman S, Bakkaloglu SA, Ekim M, Sever L, Noyan A, Aksu N. Peritonitis rates and common microorganisms in continuous ambulatory peritoneal dialysis and automated peritoneal dialysis. Pediatr Int 2009; 51:246-9.

89. Balasubramanian G, McKitty K, Fan SL. Comparing automated peritoneal dialysis with continuous ambulatory peritoneal dialysis: survival and quality of life differences? Nephrol Dial Transplant 2011; 26:1702-8.

90. Rüger W, van Ittersum FJ, Comazzetto LF, Hoeks SE, ter Wee PM. Similar peritonitis outcome in CAPD and APD patients with dialysis modality continuation during peritonitis. Perit Dial Int 2011; 31:39-47.

91. Lan PG, Johnson DW, McDonald SP, Boudville N, Borlace M, Badve SV, et al. The association between peritoneal dialysis modality and peritonitis. Clin J Am Soc Nephrol 2014; 9:1091-7.

92. Figueiredo AE, Bernardini J, Bowes E, Hiramatsu M, Price V, Su C, et al. ISPD guideline / recommendations: a syllabus for teaching peritoneal dialysis to patients and caregivers. Perit Dial Int 2016. doi.10.3747/ pdi.2015.00277 (Epub ahead of print.]

93. Bernardini J, Price V, Figueiredo A. Peritoneal dialysis patient training, 2006. Perit Dial Int 2006; 26:625-32.

94. Bender FH, Bernardini J, Piraino B. Prevention of infectious complications in peritoneal dialysis: best demonstrated practices. Kidney Int Suppl 2006: 103:S44-54

95. Hall G, Bogan A, Dreis S, Duffy A, Greene S, Kelley K, et al. New directions in peritoneal dialysis patient training. Nephrol Nurs J 2004; 31:149-63.

96. Holloway M, Mujais S, Kandert M, Warady BA. Pediatric peritoneal dialysis training: characteristics and impact on peritonitis rates. Perit Dial Int $2001 ; 21: 401-4$

97. Chow KM, Szeto CC, Law MC, Fung JS, Li PK. Influence of peritoneal dialysis training nurses' experience on peritonitis rates. Clin J Am Soc Nephrol 2007; 2:647-52.

98. Russo R, Manili L, Tiraboschi G, Amar K, De Luca M, Alberghini E, et al. Patient re-training in peritoneal dialysis: why and when it is needed. Kidney Int Suppl 2006; 103:S127-32.

99. Ballerini L, Paris V. Nosogogy: when the learner is a patient with chronic kidney failure. Kid Int 2006; 70:S122-6.

100. Arndt J. From compliance and false memory. J Exp Psych 2010; 36:66-9.

101. Bordin G, Cassati M, Sicolo N, Zuccherato N, Eduati V. Patient education in peritoneal dialysis: an observational study in Italy. J Ren Care 2007; 33:165-71.

102. Dong J, Chen Y. Impact of the bag exchange procedure on risk of peritonitis. Perit Dial Int 2010; 30:440-7.

103. Zhang L, Hawley CM, Johnson DW. Focus on peritoneal dialysis training: working to decrease peritonitis rates. Nephrol Dial Transplant 2016; 31:214-22.

104. Bernardini J, Nagy M, Piraino B. Pattern of noncompliance with dialysis exchanges in peritoneal dialysis patients. Am J Kidney Dis 2000, 35:1104-10.

105. Bernardini J, Dacko C. A survey of home visits at peritoneal dialysis centers in the United States. Perit Dial Int 1998; 18:528-31.

106. Bernardini J, Piraino B. Compliance in CAPD and CCPD patients as measured by supply inventories during home visits. Am J Kidney Dis 1998, 31:101-7.

107. Ponferrada L, Prowant BF, Schmidt LM, Burrows LM, Satalowich RJ, Bartelt C. Home visit effectiveness for peritoneal dialysis patients. ANNA J 1993; 20:333-6.

108. Kazancioglu R, Ozturk S, Ekiz S, Yucel L, Dogan S. Can using a questionnaire for assessment of home visits to peritoneal dialysis patients make a difference to the treatment outcome? J Ren Care 2008; 34:59-63.

109. Nayak KS, Sinoj KA, Subhramanyam SV, Mary B, Rao NV. Our experience of home visits in city and rural areas. Perit Dial Int 2007; 27(Suppl 2):S27-31.

110. Ellis EN, Blaszak C, Wright S, Van Lierop A. Effectiveness of home visits to pediatric peritoneal dialysis patients. Perit Dial Int 2012; 32:419-23.

111. Mawar S, Gupta S, Mahajan S. Non-compliance to the continuous ambulatory peritoneal dialysis procedure increases the risk of peritonitis. Int Urol Nephrol 2012; 44:1243-9. 
112. Ljungman S. Prevention of Peritonitis in Peritoneal Dialysis (PEPS). Available online at: https://clinicaltrials.gov/ct2/show/NCT01293799

113. Coles GA, O'Donoghue DJ, Pritchard N, Ogg CS, Jani FM, Gokal R, et al. A controlled trial of two bicarbonate-containing dialysis fluids for CAPD-final report. Nephrol Dial Transplant 1998; 13:3165-71.

114. Kim S, Oh J, Kim S, Chung W, Ahn C, Kim SG, Oh KH. Benefits of biocompatible PD fluid for preservation of residual renal function in incident CAPD patients: a 1-year study. Nephrol Dial Transplant 2009; 24:2899-908.

115. Bajo MA, Pérez-Lozano ML, Albar-Vizcaino P, del Peso G, Castro MJ, Gonzalez-Mateo G, et al. Low-GDP peritoneal dialysis fluid ('balance') has less impact in vitro and ex vivo on epithelial-to-mesenchymal transition (EMT) of mesothelial cells than a standard fluid. Nephrol Dial Transplant 2011; 26:282-91.

116. Rippe B, Simonsen 0, Heimbürger 0, Christensson A, Haraldsson B, Stelin $\mathrm{G}$, et al. Long-term clinical effects of a peritoneal dialysis fluid with less glucose degradation products. Kidney Int 2001; 59:348-57.

117. Johnson DW, Brown FG, Clarke M, Boudville N, Elias TJ, Foo MW, et al. The effects of biocompatible compared with standard peritoneal dialysis solutions on peritonitis microbiology, treatment, and outcomes: the balANZ trial. Perit Dial Int 2012; 32:497-506.

118. Fan SL, Pile T, Punzalan S, Raftery MJ, Yaqoob MM. Randomized controlled study of biocompatible peritoneal dialysis solutions: effect on residual renal function. Kidney Int 2008; 73:200-6.

119. Srivastava S, Hildebrand S, Fan SL. Long-term follow-up of patients randomized to biocompatible or conventional peritoneal dialysis solutions show no difference in peritonitis or technique survival. Kidney Int 2011; 80:986-91.

120. Cho Y, Badve SV, Hawley CM, McDonald SP, Brown FG, Boudville N, et al. Association of biocompatible peritoneal dialysis solutions with peritonitis risk, treatment, and outcomes. Clin J Am Soc Nephrol 2013; 8:1556-63.

121. Johnson DW, Brown FG, Clarke M, Boudville N, Elias TJ, Foo MW, et al. Effects of biocompatible versus standard fluid on peritoneal dialysis outcomes. J Am Soc Nephrol 2012; 23:1097-107.

122. Cho Y, Johnson DW, Badve SV, Craig JC, Strippoli GF, Wiggins KJ. The impact of neutral-pH peritoneal dialysates with reduced glucose degradation products on clinical outcomes in peritoneal dialysis patients. Kidney Int 2013; 84:969-79.

123. Strippoli GF, Tong A, Johnson D, Schena FP, Craig JC. Antimicrobial agents for preventing peritonitis in peritoneal dialysis patients. Cochrane Database Syst Rev 2004; 4:CD004679.

124. Tacconelli E, Carmeli Y, Aizer A, Ferreira G, Foreman MG, D'Agata EM. Mupirocin prophylaxis to prevent Staphylococcus aureus infection in patients undergoing dialysis: a meta-analysis. Clin Infect Dis 2003; 37:1629-38.

125. Bernardini J, Piraino B, Holley J, Johnston JR, Lutes R. A randomized trial of Staphylococcus aureus prophylaxis in peritoneal dialysis patients: mupirocin calcium ointment $2 \%$ applied to the exit site versus cyclic oral rifampin. Am J Kidney Dis 1996; 27:695-700.

126. Chu KH, Choy WY, Cheung CC, Fung KS, Tang HL, Lee W, et al. A prospective study of the efficacy of local application of gentamicin versus mupirocin in the prevention of peritoneal dialysis catheter-related infections. Perit Dial Int 2008; 28:505-8.

127. Xu G, Tu W, Xu C. Mupirocin for preventing exit-site infection and peritonitis in patients undergoing peritoneal dialysis. Nephrol Dial Transplant 2010; 25:587-92.

128. Luzar MA, Brown CB, Balf D, Hill L, Issad B, Monnier B, et al. Exit-site care and exit-site infection in continuous ambulatory peritoneal dialysis (CAPD): results of a randomized multicenter trial. Perit Dial Int 1990; 10:25-9.

129. Mahajan S, Tiwari SC, Kalra V, Bhowmik DM, Agarwal SK, Dash SC, et al. Effect of local mupirocin application on exit-site infection and peritonitis in an Indian peritoneal dialysis population. Perit Dial Int 2005; 25:473-7.

130. Lim CT, Wong KS, Foo MW. The impact of topical mupirocin on peritoneal dialysis infection in Singapore General Hospital. Nephrol Dial Transplant $2005 ; 20: 2202-6$.

131. Davenport A. Do topical antibiotics reduce exit site infection rates and peritonitis episodes in peritoneal dialysis patients? The Pan Thames
Renal Audit. J Nephrol 2012; 25:819-24.

132. Wong C, Luk IW, Ip M, You JH. Prevention of gram-positive infections in peritoneal dialysis patients in Hong Kong: a cost-effectiveness analysis. Am J Infect Control 2014; 42:412-6.

133. Aykut S, Caner C, Ozkan G, Ali C, Tugba A, Zeynep G, et al. Mupirocin application at the exit site in peritoneal dialysis patients: five years of experience. Ren Fail 2010; 32:356-61.

134. Mupirocin Study Group. Nasal mupirocin prevents Staphylococcus aureus exit-site infection during peritoneal dialysis. Mupirocin Study Group. J Am Soc Nephrol 1996; 7:2403-8.

135. Piraino B. Mupirocin for preventing peritonitis and exit site infections in patients undergoing peritoneal dialysis. Was it effective? Nephrol Dial Transplant 2010; 25:349-52.

136. Chua AN, Goldstein SL, Bell D, Brewer ED. Topical mupirocin/sodium hypochlorite reduces peritonitis and exit-site infection rates in children. Clin J Am Soc Nephrol 2009; 4:1939-43.

137. Lobbedeez T, Gardam M, Dedier H, Burdzy D, Chu M, Izatt S, et al. Routine use of mupirocin at the peritoneal catheter exit site and mupirocin resistance: still low after 7 years. Nephrol Dial Transplant 2004; 19:3140-3.

138. Perez-Fontan M, Rosales M, Rodriguez-Carmona A, Falcon TG, Valdes F. Mupirocin resistance after long-term use for Staphylococcus aureus colonization in patients undergoing chronic peritoneal dialysis. Am J Kidney Dis 2002; 39:337-41.

139. Annigeri R, Conly J, Vas S, Dedier H, Prakashan KP, Bargman JM, et al. Emergence of mupirocin-resistant Staphylococcus aureus in chronic peritoneal dialysis patients using mupirocin prophylaxis to prevent exit-site infection. Perit Dial Int 2001; 21:554-9.

140. Al-Hwiesh AK, Abdul-Rahman IS, Al-Muhanna FA, Al-Sulaiman MH, Al-Jondebi MS, Divino-Filho JC. Prevention of peritoneal dialysis catheter infections in Saudi peritoneal dialysis patients: the emergence of high-level mupirocin resistance. Int J Artif Organs 2013; 36:473-83.

141. Piraino B, Bernardini J, Florio T, Fried L. Staphylococcus aureus prophylaxis and trends in gram-negative infections in peritoneal dialysis patients. Perit Dial Int 2003; 23:456-9.

142. Mahaldar A, Weisz M, Kathuria P. Comparison of gentamicin and mupirocin in the prevention of exit-site infection and peritonitis in peritoneal dialysis. Adv Perit Dial 2009; 25:56-9.

143. Pierce DA, Williamson JC, Mauck VS, Russell GB, Palavecino E, Burkart JM. The effect on peritoneal dialysis pathogens of changing topical antibiotic prophylaxis. Perit Dial Int 2012; 32:525-30.

144. Lo MW, Mak SK, Wong YY, Lo KC, Chan SF, Tong GM, et al. Atypical mycobacterial exit-site infection and peritonitis in peritoneal dialysis patients on prophylactic exit-site gentamicin cream. Perit Dial Int 2013; 33:267-72.

145. Johnson DW, Badve SV, Pascoe EM, Beller E, Cass A, Clark C, et al. Antibacterial honey for the prevention of peritoneal-dialysis-related infections (HONEYPOT): a randomised trial. Lancet Infect Dis 2014; 14:23-30.

146. McQuillan RF, Chiu E, Nessim S, Lok CE, Roscoe JM, Tam P, et al. A randomized controlled trial comparing mupirocin and polysporin triple ointments in peritoneal dialysis patients: the MP3 Study. Clin J Am Soc Nephrol 2012; 7:297-303.

147. Montenegro J, Saracho R, Aguirre R, Martinez I, Iribar I, Ocharan J. Exit-site care with ciprofloxacin otologic solution prevents polyurethane catheter infection in peritoneal dialysis patients. Perit Dial Int 2000; 20:209-14.

148. Zimmerman SW, Ahrens E, Johnson CA, Craig W, Leggett J, O'Brien M, et al. Randomized controlled trial of prophylactic rifampin for peritoneal dialysis-related infections. Am J Kidney Dis 1991; 18:225-31.

149. Blowey DL, Warady BA, McFarland KS. The treatment of Staphylococcus aureus nasal carriage in pediatric peritoneal dialysis patients. Adv Perit Dial 1994; 10:297-99.

150. Falagas ME, Fragoulis KN, Bliziotis IA. Oral rifampin for prevention of $S$. aureus carriage-related infections in patients with renal failure-a meta-analysis of randomized controlled trials. Nephrol Dial Transplant 2006; 21:2536-42.

151. Churchill DN, Taylor DW, Vas SI. Peritonitis in continuous ambulatory peritoneal dialysis patients: a randomized clinical trial of cotrimoxazole prophylaxis. Perit Dial Int 1988; 8:125-8.

152. Low DE, Vas SI, Oreopoulos DG, Manuel MA, Saiphoo MM, Finer C, et al. This single copy is for your personal, non-commercial use only.

For permission to reprint multiple copies or to order presentation-ready

copies for distribution, contact Multimed Inc. at marketing@multi-med.com 
Prophylactic cephalexin ineffective in chronic ambulatory peritoneal dialysis. Lancet 1980; 2:753-4.

153. Sesso R, Parisio K, Dalboni A, Rabelo T, Barbosa D, Cendoroglo M, et al. Effect of sodium fusidate and ofloxacin on Staphylococcus aureus colonization and infection in patients on continuous ambulatory peritoneal dialysis. Clin Nephrol 1994; 41:370-6.

154. van Diepen AT, Jassal SV. A qualitative systematic review of the literature supporting a causal relationship between exit-site infection and subsequent peritonitis in patients with end-stage renal disease treated with peritoneal dialysis. Perit Dial Int 2013; 33:604-10.

155. Lloyd A, Tangri N, Shafer LA, Rigatto C, Perl J, Komenda P, et al. The risk of peritonitis after an exit site infection: a time-matched, case-control study. Nephrol Dial Transplant 2013; 28:1915-21.

156. Fried L, Bernardini J, Johnston JR, Piraino B. Peritonitis influences mortality in peritoneal dialysis patients. J Am Soc Nephrol 1996; 7:2176-82.

157. Yip T, Tse KC, Lam MJ, Cheng SW, Lui SL, Tang S, et al. Risks and outcomes of peritonitis after flexible colonoscopy in CAPD patients. Perit Dial Int 2007; 27:560-4.

158. Machuca E, Ortiz AM, Rabagliata R. Streptococcus viridian-associated peritonitis after gastroscopy. Adv Perit Dial 2005; 21:60-2.

159. Poortvliet W, Selten HP, Raasveld MH, Klemt-Kropp M. CAPD peritonitis after colonoscopy: follow the guidelines. Neth J Med 2010; 68:377-8.

160. Holley JL, Udekwu A, Rault R, Piraino B. The risks of laparoscopic cholecystectomy in CAPD compared with hemodialysis patients: a study of ten patients. Perit Dial Int 1994; 14(Suppl 1):S27-9.

161. Wu HH, Li IJ, Weng CH, Lee CC, Chen YC, Chang MY, et al. Prophylactic antibiotics for endoscopy-associated peritonitis in peritoneal dialysis patients. PLOS ONE 2013; 8:e71532.

162. Singharetnam W, Holley JL. Acute treatment of constipation may lead to transmural migration of bacteria resulting in gram-negative, polymicrobial, or fungal peritonitis. Perit Dial Int 1996; 16:423-5.

163. Wood CF, Fleming V, Tunridge J, Thomson N, Atkins RC. Campylobacter peritonitis in continuous ambulatory peritoneal dialysis: report of eight cases and a review of the literature. Am J Kidney Dis 1992; 19:257-63.

164. Su CY, Pei J, Lu XH, Tang W, Wang T. Gastrointestinal symptoms predict peritonitis rates in CAPD patients. Clin Nephrol 2012; 77:267-74.

165. Chuan YW, Shu KH, Yu TM, Cheng CH. Hypokalaemia: an independent risk factor of Enterobacteriaceae peritonitis in CAPD patients. Nephrol Dial Transplant 2009; 24:1603-8.

166. Szeto CC, Kwan BC, Chow KM, Law MC, Pang WF, Chung KY, et al. Recurrent and relapsing peritonitis: causative organisms and response to treatment. Am J Kidney Dis 2009; 54:702-10.

167. Shu KH, Chang CS, Chuang YW, Chen $\mathrm{CH}$, Cheng $\mathrm{CH}$, Wu MJ, et al. Intestinal bacterial overgrowth in CAPD patients with hypokalaemia. Nephrol Dial Transplant 2009; 24:1289-92

168. Chuang YW, Shu KH, Yu TM, Cheng CH, Chen CH. Hypokalaemia: an independent risk factor of Enterobacteriaceae peritonitis in CAPD patients. Nephrol Dial Transplant 2009; 24:1603-8.

169. Afsar B, Elsurer R, Bilgic A, Sezer S, Ozdemir F. Regular lactulose use is associated with lower peritonitis rates: an observational study. Perit Dial Int 2010; 30:243-6.

170. Li PK, Leung CB, Leung AK, Luk WK, Lai KN. Posthysteroscopy fungal peritonitis in a patient on continuous ambulatory peritoneal dialysis. Am J Kidney Dis 1993; 21:446-8.

171. Ceri M, Altay M, Unverdi S, Kurultak I, Duranay M. An unusual presentation of vaginal leakage in a peritoneal dialysis patient. Perit Dial Int 2010; 30:663-5.

172. Cobelo C, Ros S, Trujillo C, Garcia P. An unusual case of vaginal leak in a patient on peritoneal dialysis. Perit Dial Int 2010; 30:665-6.

173. Neumann JL, Moran J. Peritonitis due to a peritoneal vaginal fistula. Nephrol Nurs J 2010; 37:177-8.

174. Yildiz N, Turhan P, Biglic 0, Erguven M, Candan C. Vaginal dialysate leak in a child on peritoneal dialysis. Perit Dial Int 2010; 30:666-7.

175. Shukla A, Abreu Z, Bargman JM. Streptococcal PD peritonitis-a 10-year review of one centre's experience. Nephrol Dial Transplant 2006; 21:3545-9.

176. Levy M, Balfe JW, Geary D, Fryer-Keene SP. Factors predisposing and contributing to peritonitis during chronic peritoneal dialysis in children: a ten-year experience. Perit Dial Int 1990; 10:263-9.

177. Prasad N, Gupta A, Sharma RK, Sinha A, Kumar R. Impact of nutritional status on peritonitis in CAPD patients. Perit Dial Int 2007; 27:42-7.

178. Wang W, Bernardini J, Piraino B, Fried L. Albumin at the start of peritoneal dialysis predicts the development of peritonitis. Am J Kidney Dis 2003; 41:664-9.

179. Troidel L, WatnickS, Wuerth DB, Gorban-Brennan N, Kliger AS, Finkelstein F0. Depression and its association with peritonitis in long-term peritoneal dialysis patients. Am J Kidney Dis 2003; 42:350-4.

180. Paudel K, Namagondlu G, Samad N, McKitty K, Fan SL. Lack of motivation: a new modifiable risk factor for peritonitis in patients undergoing peritoneal dialysis? J Ren Care 2015; 41:33-42.

181. Satomura A, Yanai M, Fujita T, Arashima Y, Kumasaka K, Nakane C, et al. Paterurella multocida: molecular evidence of zoonotic etiology. Ther Apher Dial 2010; 14:373-6.

182. Broughton A, Verger C, Goffin E. Pets-related peritonitis in peritoneal dialysis: companion animals or Trojan horses? Semin Dial 2010; 23:306-16.

183. Rudnicki M, Kerschbaum J, Hausdorfer J, Mayer G, Konig P. Risk factors for peritoneal dialysis-associated peritonitis: the role of oral active vitamin D. Perit Dial Int 2010; 30:541-8.

184. Kerschbaum J, Vychytil A, Lhotta K, Prischl FC, Wiesholzer M, MachholdFabrizii V, et al. Treatment with oral active vitamin $D$ is associated with decreased risk of peritonitis and improved survival in patients on peritoneal dialysis. PLOS ONE 2013; 8:e67836.

185. Wang J, Zhang H, Liu J, Zhang K, Yi B, Liu Y, et al. Implementation of a continuous quality improvement program reduces the occurrence of peritonitis in PD. Ren Fail 2014; 36:1029-32.

186. Qamar M, Sheth H, Bender FH, Piraino B. Clinical outcomes in peritoneal dialysis: impact of continuous quality improvement initiatives. Adv Perit Dial 2009; 25:76-9.

187. Prasad KN, Prasad N, Gupta A, Sharma RK, Verma AK, Ayyagari A. Fungal peritonitis in patients on continuous ambulatory peritoneal dialysis: a single centre Indian experience. $J$ Infect 2004; 48:96-101.

188. Wang AY, Yu AW, Li PK, Lam PK, Leung CB, Lai KN, et al. Factors predicting outcome of fungal peritonitis in peritoneal dialysis: analysis of a 9-year experience of fungal peritonitis in a single center. Am J Kidney Dis 2000; 36:1183-92.

189. Goldie SJ, Kiernan-Troidle L, Torres C, Gorban-Brennan N, Dunne D, Kliger AS, et al. Fungal peritonitis in a large chronic peritoneal dialysis population: a report of 55 episodes. Am J Kidney Dis 1996; 28:86-91.

190. Zaruba K, Peters J, Jungbluth H. Successful prophylaxis for fungal peritonitis in patients on continuous ambulatory peritoneal dialysis: six years' experience. Am J Kidney Dis 1991; 17:43-6.

191. Robitaille P, Merouani A, Clermont MJ, Hebert E. Successful antifungal prophylaxis in chronic peritoneal dialysis: a pediatric experience. Perit Dial Int 1995; 15:77-9.

192. Lo WK, Chan CY, Cheng SW, Poon JF, Chan DT, Cheng IK. A prospective randomized control study of oral nystatin prophylaxis for Candida peritonitis complicating continuous ambulatory peritoneal dialysis. Am J Kidney Dis 1996; 28:549-52.

193. Wong PN, Lo KY, Tong GM, Chan SF, Lo MW, Mak SK, et al. Prevention of fungal peritonitis with nystatin prophylaxis in patients receiving CAPD. Perit Dial Int 2007; 27:531-6.

194. Thodis E, Vas SI, Bargman JM, Singhal M, Chu M, Oreopoulos DG. Nystatin prophylaxis: its inability to prevent fungal peritonitis in patients on continuous ambulatory peritoneal dialysis (see Comment). Perit Dial Int 1998; 18:583-9.

195. Williams PF, Moncrieff N, Marriott J. No benefit in using nystatin prophylaxis against fungal peritonitis in peritoneal dialysis patients. Perit Dial Int 2000; 20:352-3.

196. Wadhwa NK, Suh H, Cabralda T. Antifungal prophylaxis for secondary fungal peritonitis in peritoneal dialysis patients. Adv Perit Dial 1996; 12:189-91.

197. Restrepo C, Chacon J, Manjarres G. Fungal peritonitis in peritoneal dialysis patients: successful prophylaxis with fluconazole, as demonstrated by prospective randomized control trial. Perit Dial Int 2010; 30:619-25.

198. Davenport A, Wellsted D. Does antifungal prophylaxis with daily oral

This single copy is for your personal, non-commercial use only.

For permission to reprint multiple copies or to order presentation-ready

copies for distribution, contact Multimed Inc. at marketing@multi-med.com 
fluconazole reduce the risk of fungal peritonitis in peritoneal dialysis patients? The Pan Thames Renal Audit. Blood Purif 2011; 32:181-5.

199. Lopes K, Rocha A, Rodrigues A, Carvalho MJ, Cabrita A. Long-term peritoneal dialysis experience: quality control supports the use of fluconazole to prevent fungal peritonitis. Int J Artif Organs 2013; 36:484-8.

200. Kumar KV, Mallikarjuna HM, Gokulnath, Jayanthi S. Fungal peritonitis in continuous ambulatory peritoneal dialysis: The impact of antifungal prophylaxis on patient and technique outcomes. Indian J Nephrol 2014 24:297-301.

201. Finkelstein ES, Jekel J, Troidle L, Gorban-Brennan N, Finkelstein F0, Bia FJ. Patterns of infection inpatients maintained on long-term peritoneal dialysis therapy with multiple episodes of peritonitis. Am J Kidney Dis 2002; 39:1278-86

202. Piraino B. Peritoneal dialysis catheter replacement: save the patient and not the catheter. Sem Dial 2003; 16:72-5.

203. Ballinger AE, Palmer SC, Wiggins KJ, Craig JC, Johnson DW, Cross NB, et al. Treatment for peritoneal dialysis-associated peritonitis. Cochrane Database Syst Rev 2014; 4:CD005284.

204. Cancarini GC, Manili L, Brunori G, Camerini C, Zubani R, Colombrita D, et al. Simultaneous catheter replacement/removal during infectious complications in peritoneal dialysis. Adv Perit Dial 1994; 10:210-3.

205. Lui SL, Yip T, Tse KC, Lam MF, Lai KN, Lo WK. Treatment of refractory Pseudomonas aeruginosa exit-site infection by simultaneous removal and reinsertion of peritoneal dialysis catheter. Perit Dial Int 2005; 25:560-3.

206. Rocklin MA, Teitelbaum I. Noninfectious causes of cloudy peritoneal dialysate. Semin Dial 2001; 14:37-40.

207. Gould IM, Casewell MW. The laboratory diagnosis of peritonitis during continuous ambulatory peritoneal dialysis. J Hosp Infect 1986; 7:155-60.

208. Flanigan MJ, Freeman RM, Lim VS. Cellular response to peritonitis among peritoneal dialysis patients. Am J Kidney Dis 1985; 6:420-4.

209. Lee CC, Sun CY, Chang KC, Wu MS. Positive dialysate gram stain predicts outcome of empirical antibiotic therapy for peritoneal dialysis-associated peritonitis. Ther Apher Dial 2010; 14:201-8.

210. Alfa MJ, Degagne P, Olson N, Harding GK. Improved detection of bacterial growth in continuous ambulatory peritoneal dialysis effluent by use of BacT/Alert FAN bottles. J Clin Microbiol 1997; 35:862-6.

211. Azap OK, Timurkaynak F, Sezer S, Cağir U, Yapar G, Arslan H, et al. Value of automatized blood culture systems in the diagnosis of continuous ambulatory peritoneal dialysis peritonitis. Transplant Proc 2006; 38:411-2.

212. Sewell DL, Golper TA, Hulman PB, Thomas CM, West LM, Kubey WY, et al. Comparison of large volume culture to other methods for isolation of microorganisms from dialysate. Perit Dial Int 1990; 10:49-52.

213. Chow KM, Chow VC, Szeto CC, Law MC, Leung CB, Li PK. Continuous ambulatory peritoneal dialysis peritonitis: broth inoculation culture versus water lysis method. Nephron Clin Pract 2007; 105(3):c121-5.

214. Iyer RN, Reddy AK, Gande S, Aiyangar A. Evaluation of different culture methods for the diagnosis of peritonitis in patients on continuous ambulatory peritoneal dialysis. Clin Microbiol Infect 2014; 20:0294-6.

215. ParkSJ, LeeJY, TakWT, LeeJH. Using reagent strips for rapid diagnosis of peritonitis in peritoneal dialysis patients. Adv Perit Dial 2005; 21:69-71.

216. Akman S, Uygun V, Guven AG. Value of the urine strip test in the early diagnosis of bacterial peritonitis. Pediatr Int 2005; 47:523-7.

217. Nguyen-Khac E, Cadranel JF, Thevenot T, Nousbaum JB. Review article: The utility of reagent strips in the diagnosis of infected ascites in cirrhotic patients. Aliment Pharmacol Ther 2008; 28:282-8.

218. Yoo TH, Chang KH, Ryu DR, Kim JS, Choi HY, Park HC, et al. Usefulness of $23 \mathrm{~S}$ rRNA amplification by PCR in the detection of bacteria in CAPD peritonitis. Am J Nephrol 2006; 26:115-20.

219. Johnson G, Wilks M, Warwick S, Millar MR, Fan SL. Comparative study of diagnosis of PD peritonitis by quantitative polymerase chain reaction for bacterial DNA vs culture methods. J Nephrol 2006; 19:45-9.

220. Ro Y, Hamada C, Io H, Hayashi K, Hirahara I, Tomino Y. Rapid, simple, and reliable method for the diagnosis of CAPD peritonitis using the new MMP-9 test kit. J Clin Lab Anal 2004; 18:224-30.

221. Ota K, Maruyama H, Iino N, Nakamura G, Shimotori M, Tanabe Y, et al. Rapid detection of causative pathogen of peritonitis using in-situ hybridization in a patient with continuous ambulatory peritoneal dialysis. $J$ Infect Chemother 2007; 13:273-5.
222. Kim SH, Jeong HS, Kim YH, Song SA, Lee JY, Oh SH, et al. Evaluation of DNA extraction methods and their clinical application for direct detection of causative bacteria in continuous ambulatory peritoneal dialysis culture fluids from patients with peritonitis by using broad-range PCR. Ann Lab Med 2012; 32:119-25.

223. Chang YT, Wang HC, Wang MC, Wu AB, Sung JM, Sun HS, et al. Rapid identification of bacteria and Candida pathogens in peritoneal dialysis effluent from patients with peritoneal dialysis-related peritonitis by use of multilocus PCR coupled with electrospray ionization mass spectrometry. J Clin Microbiol 2014; 52:1217-9.

224. Ahmadi SH, Neela V, Hamat RA, Goh BL, Syafinaz AN. Rapid detection and identification of pathogens in patients with continuous ambulatory peritoneal dialysis (CAPD) associated peritonitis by 16s rRNA gene sequencing. Trop Biomed 2013; 30:602-7.

225. Lin CY, Roberts GW, Kift-Morgan A, Donovan KL, Topley N, Eberl M. Pathogen-specific local immune fingerprints diagnose bacterial infection in peritoneal dialysis patients. J Am Soc Nephrol 2013; 24:2002-9.

226. Bieber SD, Anderson AE, Mehrotra R. Diagnostic testing for peritonitis in patients undergoing peritoneal dialysis. Semin Dial 2014; 27:602-6.

227. Barretti P, Doles JV, Pinotti DG, El Dib R. Efficacy of antibiotic therapy for peritoneal dialysis-associated peritonitis: a proportional meta-analysis. BMC Infect Dis 2014; 14:445.

228. Flanigan MJ, Lim VS. Initial treatment of dialysis associated peritonitis: A controlled trial of vancomycin versus cefazolin. Perit Dial Int 1991; 11:31-7.

229. Lupo A, Rugiu C, Bernich P, Laudon A, Marcantoni C, Mosconi G, et al. A prospective, randomized trial of two antibiotic regimens in the treatment of peritonitis in CAPD patients: teicoplanin plus tobramycin versus cephalothin plus tobramycin. J Antimicrob Chemother 1997; 40:729-32.

230. Khairullah Q, Provenzano R, Tayeb J, Ahmad A, Balakrishnan R, Morrison L. Comparison of vancomycin versus cefazolin as initial therapy for peritonitis in peritoneal dialysis patients. Perit Dial Int 2002; 22:339-44.

231. Gucek A, Bren AF, Hergouth V, Lindic J. Cefazolin and netilmicin versus vancomycin and ceftazidime in the treatment of CAPD peritonitis. Adv Perit Dial 1997; 13:218-20.

232. Zelenitsky S, Barns L, Findlay I, Alfa M, Ariano R, Fine A, et al. Analysis of microbiological trends in peritoneal dialysis-related peritonitis from 1991 to 1998. Am J Kidney Dis 2000; 36:1009-13.

233. Lui SL, Cheng SW, Ng F, Ng SY, Wan KM, Yip T, et al. Cefazolin plus netilmicin versus cefazolin plus ceftazidime for treating CAPD peritonitis: effect on residual renal function. Kidney Int 2005; 68:2375-80.

234. Wong KM, Chan YH, Cheung CY, Chak WL, Choi KS, Leung SH, et al. Cefepime versus vancomycin plus netilmicin therapy for continuous ambulatory peritoneal dialysis associated peritonitis. Am J Kidney Dis $2001 ; 38: 127-31$

235. Kobayashi K, Nakamoto H, Okada S, Hoshitani K, Uchida K, Arima H, et al. Efficacy and safety of meropenem plus tobramycin followed by meropenem plus vancomycin for treating peritonitis in patients on continuous ambulatory peritoneal dialysis. Adv Perit Dial 2006; 22:65-8.

236. Leung CB, Szeto CC, Chow KM, Kwan BC, Wang AY, Lui SF, et al. Cefazolin plus ceftazidime versus imipenem/cilastatin monotherapy for treatment of CAPD peritonitis-a randomized controlled trial. Perit Dial Int 2004; 24:440-6.

237. Goffin E, Herbiet L, Pouthier D, Pochet JM, Lafontaine JJ, Christophe $\mathrm{JL}$, et al. Vancomycin and ciprofloxacin: systemic antibiotic administration for peritoneal dialysis-associated peritonitis. Perit Dial Int 2004; 24:433-9.

238. Lima RC, Barreira A, Cardoso FL, Lima MH, Leite M Jr. Ciprofloxacin and cefazolin as a combination for empirical initial therapy of peritoneal dialysis-related peritonitis: five-year follow-up. Perit Dial Int 2007; 27:56-60.

239. Cheng IK, Fang GX, Chau PY, Chan TM, Tong KL, Wong AK, et al. A randomized prospective comparison of oral levofloxacin plus intraperitoneal (IP) vancomycin and IP netromycin plus IP vancomycin as primary treatment of peritonitis complicating CAPD. Perit Dial Int 1998; 18:371-5.

240. Lye WC, Lee EJ, van der Straaten J. Intraperitoneal vancomycin/oral pefloxacin versus intraperitoneal vancomycin/gentamicin in the treatment of continuous ambulatory peritoneal dialysis peritonitis. Perit Dial

This single copy is for your personal, non-commercial use only.

For permission to reprint multiple copies or to order presentation-ready

copies for distribution, contact Multimed Inc. at marketing@multi-med.com 
Int 1993; 13(Suppl 2):S348-50.

241. Chan MK, Cheng IK, Ng WS. A randomized prospective trial of three different regimens of treatment of peritonitis in patients on continuous ambulatory peritoneal dialysis. Am J Kidney Dis 1990; 15:155-9.

242. Fuiano G, Sepe V, Viscione M, Nani E, Conte G. Effectiveness of single daily intraperitoneal administration of aztreonam and cefuroxime in the treatment of peritonitis in continuous ambulatory peritoneal dialysis (CAPD). Perit Dial Int 1989; 9:273-5.

243. Gerig JS, Bolton ND, Swabb EA, Scheld WM, Bolton WK. Effect of hemodialysis and peritoneal dialysis on aztreonam pharmacokinetics. Kidney Int 1984; 26:308-18.

244. Anwar N, Merchant M, Were T, Tooth A, Uttley L, Gokal R. A prospective, randomized study of the comparative safety and efficacy of intraperitoneal imipenem versus vancomycin and netilmicin in the treatment of peritonitis on CAPD. Perit Dial Int 1995; 15:167-71.

245. Baker RJ, Senior H, Clemenger M, Brown EA. Empirical aminoglycosides for peritonitis do not affect residual renal function. Am J Kidney Dis 2003; 41:670-5.

246. Szeto CC, Kwan BC, Chow KM, Chung S, Yu V, Cheng PM, et al. Predictors of residual renal function decline in patients undergoing continuous ambulatory peritoneal dialysis. Perit Dial Int 2015; 35:180-8.

247. Badve SV, Hawley CM, McDonald SP, Brown FG, Boudville NC, Wiggins KJ, et al. Use of aminoglycosides for peritoneal dialysis-associated peritonitis does not affect residual renal function. Nephrol Dial Transplant 2012; 27:381-7.

248. Altmann P, Butter K, Cunningham J, Drew P, Goodwin F, Marsh F. CAPD peritonitis: 10 or 21 days treatment? Kidney Int 1984; 26:544.

249. Tokgoz B, Somdas MA, Ucar C, Kocyigit I, Unal A, Sipahioglu MH, et al. Correlation between hearing loss and peritonitis frequency and administration of ototoxic intraperitoneal antibiotics in patients with CAPD. Ren Fail 2010; 32:179-84.

250. Wiggins KJ, Craig JC, Johnson DW, Strippoli GF. Treatment for peritoneal dialysis-associated peritonitis. Cochrane Database Syst Rev 2008; 1:CD005284.

251. Fontán MP, Cambre HD, Rodríguez-Carmona A, Muñiz AL, Falcón TG. Treatment of peritoneal dialysis-related peritonitis with ciprofloxacin monotherapy: clinical outcomes and bacterial susceptibility over two decades. Perit Dial Int 2009; 29:310-8.

252. Celik A, Cirit M, Tünger A, Akçiçek F, Basçi A. Treatment of CAPD peritonitis with oral trimethoprim/sulfamethoxazole and intraperitoneal aminoglycoside combination. Perit Dial Int 1999; 19:284-5.

253. Lam MF, Tang BS, Tse KC, Chan TM, Lai KN. Ampicillin-sulbactam and amikacin used as second-line antibiotics for patients with culture-negative peritonitis. Perit Dial Int 2008; 28:540-2.

254. Tosukhowong T, Eiam-Ong S, Thamutok K, Wittayalertpanya S, Na Ayudhya DP. Pharmacokinetics of intraperitoneal cefazolin and gentamicin in empiric therapy of peritonitis in continuous ambulatory peritoneal dialysis patients. Perit Dial Int 2001; 21:587-94.

255. de Paepe M, Lameire N, Belpaire F, Bogaert M. Peritoneal pharmacokinetics of gentamicin in man. Clin Nephrol 1983; 19:107-9.

256. Lye WC, Wong PL, van der Straaten JC, Leong S0, Lee EJ. A prospective randomized comparison of single versus multidose gentamicin in the treatment of CAPD peritonitis. Adv Perit Dial 1995; 11:179-81.

257. Neale TJ, Malani J, Humble M. Netilmicin in the treatment of clinical peritonitis in chronic renal failure patients managed by continuous ambulatory peritoneal dialysis. N Z Med J 1987; 100:374-7.

258. Bunke CM, Aronoff GR, Brier ME, Sloan RS, Luft FC. Tobramycin kinetics during continuous ambulatory peritoneal dialysis. Clin Pharmacol Ther 1983; 34:110-6.

259. Bunke CM, AronoffGR, Luft FC. Pharmacokinetics of common antibiotics used in continuous ambulatory peritoneal dialysis. Am J Kidney Dis 1983; 3:114-7.

260. Manley HJ, Bailie GR, Frye R, Hess LD, McGoldrick MD. Pharmacokinetics of intermittent intravenous cefazolin and tobramycin in patients treated with automated peritoneal dialysis. J Am Soc Nephrol 2000; 11:1310-6.

261. Manley HJ, Bailie GR, Asher RD, Eisele G, Frye RF. Pharmacokinetics of intermittent intraperitoneal cefazolin in continuous ambulatory peritoneal dialysis patients. Perit Dial Int 1999; 19:65-70.
262. Yuen SK, Yuen YP, Fok SP, Yong SP, Tse MW, Chan AY. A novel intraperitoneal cefepime regime based on pharmacokinetic modeling to treat CAPD peritonitis. Perit Dial Int 2010; 30:660-1.

263. Li PK, Ip M, Law MC, Szeto CC, Leung CB, Wong TY, et al. Use of intraperitoneal cefepime as monotherapy in treatment of CAPD peritonitis. Perit Dial Int 2000; 20:232-4.

264. Leehey DJ, Reid R, Chan AY, Ing TS. Cefoperazone in the treatment of peritonitis in continuous ambulatory peritoneal dialysis patients. Artif Organs 1988; 12:482-3.

265. Hodler JE, Galeazzi RL, Frey B, Rudhardt M, Seiler AJ. Pharmacokinetics of cefoperazone in patients undergoing chronic ambulatory peritoneal dialysis: clinical and pathophysiological implications. EurJ Clin Pharmacol 1984; 26:609-12.

266. Albin HC, Demotes-Mainard FM, Bouchet JL, Vincon GA, Martin-Dupont C. Pharmacokinetics of intravenous and intraperitoneal cefotaxime in chronic ambulatory peritoneal dialysis. Clin Pharmacol Ther 1985; 38:285-9.

267. Booranalertpaisarn V, Eiam-Ong S, Wittayalertpanya S, Kanjanabutr T, Na Ayudhya DP. Pharmacokinetics of ceftazidime in CAPD-related peritonitis. Perit Dial Int 2003; 23:574-9.

268. Grabe DW, Bailie GR, Eisele G, Frye RF. Pharmacokinetics of intermittent intraperitoneal ceftazidime. Am J Kidney Dis 1999; 33:111-7.

269. Albin H, Ragnaud JM, Demotes-Mainard F, Vinçon G, Couzineau M, Wone C. Pharmacokinetics of intravenous and intraperitoneal ceftriaxone in chronic ambulatory peritoneal dialysis. Eur J Clin Pharmacol 1986; 31:479-83.

270. Bulger RJ, Bennett JV, Boen ST. Intraperitoneal administration of broad-spectrum antibiotics in patients with renal failure. JAMA 1965 194:1198-1202.

271. Bierhoff M, Krutwagen E, van Bommel EF, Verburgh CA. Listeria peritonitis in patients on peritoneal dialysis: two cases and a review of the literature. Neth J Med 2011; 69:461-4.

272. Lunde NM, Messana JM, Swartz RD. Unusual causes of peritonitis in patients undergoing continuous peritoneal dialysis with emphasis on Listeria monocytogenes. J Am Soc Nephrol 1992; 3:1092-7.

273. Ahmad M, Krishnan A, Kelman E, Allen V, Bargman JM. Listeria monocytogenes peritonitis in a patient on peritoneal dialysis: a case report and review of the literature. Int Urol Nephrol 2008; 40:815-9.

274. Blackwell BG, Leggett JE, Johnson CA, Zimmerman SW, Craig WA. Ampicillin and sulbactam pharmacokinetics and pharmacodynamics in continuous ambulatory peritoneal dialysis (CAPD). Perit Dial Int 1990; 10:221-6.

275. Zaidenstein R, Weissgarten J, Dishi V, Koren M, Soback S, Gips M, et al. Pharmacokinetics of intraperitoneal piperacillin/tazobactam in patients on peritoneal dialysis with and without pseudomonas peritonitis. Perit Dial Int 2000; 20:227-31.

276. Cheng IK, Chan CY, Wong WT, Cheng SW, Ritchie CW, Cheung WC, et al. A randomized prospective comparison of oral versus intraperitoneal ciprofloxacin as the primary treatment of peritonitis complicating continuous ambulatory peritoneal dialysis. Perit Dial Int 1993; 13(Suppl 2):S351-4.

277. Chang MJ, Namgung H, Choi HD, Song YR, Kim SG, Oh JM, et al. Pharmacokinetics of clindamycin in the plasma and dialysate after intraperitoneal administration of clindamycin phosphoester to patients on continuous ambulatory peritoneal dialysis: an open-label, prospective, single-dose, two-institution study. Basic Clin Pharmacol Toxicol 2012; 110:504-9.

278. Huen SC, Hall I, Topal J, Mahnensmith RL, Brewster UC, Abu-Alfa AK. Successful use of intraperitoneal daptomycin in the treatment of vancomycin-resistant enterococcus peritonitis. Am J Kidney Dis 2009, 54:538-41.

279. Cheng IK, Lui SL, Fang GX, Chau PY, Cheng SW, Chiu FH. A randomized prospective comparison of oral versus intraperitoneal ofloxacin as the primary treatment of CAPD peritonitis. Nephrology (Carlton) 1997; 3:431-5.

280. Fitzpatrick MA, EsterlyJS, Postelnick MJ, Sutton SH. Successful treatment of extensively drug-resistant Acinetobacter baumannii peritoneal dialysis peritonitis with intraperitoneal polymyxin $B$ and ampicillin-sulbactam. Ann Pharmacother 2012; 46:e17.

281. Lynn WA, Clutterbuck E, Want S, Markides V, Lacey S, Rogers TR, et al.

This single copy is for your personal, non-commercial use only. For permission to reprint multiple copies or to order presentation-ready copies for distribution, contact Multimed Inc. at marketing@multi-med.com 
Treatment of CAPD-peritonitis due to glycopeptide-resistant Enterococcus faecium with quinupristin / dalfopristin. Lancet 1994; 344:1025-6.

282. Vlaar PJ, van Hulst M, Benne CA, Janssen WM. Intraperitoneal compared with intravenous meropenem for peritoneal dialysis-related peritonitis. Perit Dial Int 2013; 33:708-9.

283. Liakopoulos V, Leivaditis K, Nikitidou 0, Divani M, Antoniadi G, Dombros N. Intermittent intraperitoneal dose of teicoplanin in peritoneal dialysisrelated peritonitis. Perit Dial Int 2012; 32:365-6.

284. Fish R, Nipah R, Jones C, Finney H, Fan SL. Intraperitoneal vancomycin concentrations during peritoneal dialysis-associated peritonitis: correlation with serum levels. Perit Dial Int 2012; 32:332-8.

285. Bunke CM, Aronoff GR, Brier ME, Sloan RS, Luft FC. Vancomycin kinetics during continuous ambulatory peritoneal dialysis. Clin Pharmacol Ther 1983; 34:631-7.

286. Dahl NV, Foote EF, Searson KM, Fein JL, Kapoian T, Steward CA, et al. Pharmacokinetics of intraperitoneal fluconazole during continuous cycling peritoneal dialysis. Ann Pharmacother 1998; 32:1284-9.

287. Roberts DM, Kauter G, Ray JE, Gillin AG. Intraperitoneal voriconazole in a patient with Aspergillus peritoneal dialysis peritonitis. Perit Dial Int 2013; 33:92-3.

288. Koomanachai P, Landersdorfer CB, Chen G, Lee HJ, Jitmuang A, Wasuwattakul $\mathrm{S}$, et al. Pharmacokinetics of colistin methanesulfonate and formed colistin in end-stage renal disease patients receiving continuous ambulatory peritoneal dialysis. Antimicrob Agents Chemother 2014; 58:440-6.

289. Cardone KE, Grabe DW, Kulawy RW, Daoui R, Roglieri J, Meola S, et al. Ertapenem pharmacokinetics and pharmacodynamics during continuous ambulatory peritoneal dialysis. Antimicrob Agents Chemother 2012 56:725-30.

290. DePestel DD, Peloquin CA, Carver PL. Peritoneal dialysis fluid concentrations of linezolid in the treatment of vancomycin-resistant Enterococcus faecium peritonitis. Pharmacotherapy 2003; 23:1322-6.

291. Song IJ, Seo JW, Kwon YE, Kim YL, Lim TS, Kang EW, et al. Successful treatment of vancomycin-resistant enterococcus peritonitis using linezolid without catheter removal in a peritoneal dialysis patient. Perit Dial Int 2014; 34:235-9.

292. Yang JW, Kim YS, Choi SO, Han BG. Successful use of intravenous linezolid in CAPD patient with vancomycin-resistant enterococcal peritonitis. Perit Dial Int 2011; 31:209-10.

293. Skalioti C, Tsaganos T, Stamatiadis D, Giamarellos-Bourboulis EJ, Boletis $\mathrm{J}$, Kanellakopoulou K. Pharmacokinetics of moxifloxacin in patients undergoing continuous ambulatory peritoneal dialysis. Perit Dial Int 2009; 29:575-9.

294. Zimmerman SW, Ahrens E, Johnson CA, Craig W, Leggett J, O'Brien M, et al. Randomized controlled trial of prophylactic rifampin for peritoneal dialysis-related infections. Am J Kidney Dis 1991; 18:225-31.

295. Blowey DL, Warady BA, McFarland KS. The treatment of Staphylococcus aureus nasal carriage in pediatric peritoneal dialysis patients. Adv Perit Dial 1994; 10:297-9.

296. Wong PN, Lo KY, Tong GM, Chan SF, Lo MW, Mak SK, et al. Treatment of fungal peritonitis with a combination of intravenous amphotericin $\mathrm{B}$ and oral flucytosine, and delayed catheter replacement in continuous ambulatory peritoneal dialysis. Perit Dial Int 2008; 28:155-62.

297. Madariaga MG, Tenorio A, Proia L. Trichosporon inkin peritonitis treated with caspofungin. J Clin Microbiol 2003; 41:5827-9.

298. Fourtounas C, Marangos M, Kalliakmani P, Savidaki E, Goumenos DS, Vlachojannis JG. Treatment of peritoneal dialysis related fungal peritonitis with caspofungin plus amphotericin B combination therapy. Nephrol Dial Transplant 2006; 21:236-7.

299. Chan TM, Chan CY, Cheng SW, Lo WK, Lo CY, Cheng IK. Treatment of fungal peritonitis complicating continuous ambulatory peritoneal dialysis with oral fluconazole: a series of 21 patients. Nephrol Dial Transplant 1994; 9:539-42.

300. Sedlacek M, Cotter JG, Suriawinata AA, Kaneko TM, Zuckerman RA, Parsonnet J, et al. Mucormycosis peritonitis: more than 2 years of disease-free follow-up after posaconazole salvage therapy after failure of liposomal amphotericin B. Am J Kidney Dis 2008; 51:302-6.

301. Ghebremedhin B, Bluemel A, Neumann KH, Koenig B, Koenig W.
Peritonitis due to Neosartorya pseudofischeri in an elderly patient undergoing peritoneal dialysis successfully treated with voriconazole. J Med Microbiol 2009; 58:678-82.

302. Ulusoy S, Ozkan G, Tosun I, Kaynar K, Köksal I, Türkyilmaz S, et al. Peritonitis due to Aspergillus nidulans and its effective treatment with voriconazole: the first case report. Perit Dial Int 2011; 31:212-3.

303. Terada M, Ohki E, Yamagishi Y, Nishiyama Y, Satoh K, Uchida K, et al. Fungal peritonitis associated with Curvularia geniculata and Pithomyces species in a patient with vulvar cancer who was successfully treated with oral voriconazole. J Antibiot (Tokyo) 2014; 67:191-3.

304. Blunden M, Zeitlin D, Ashman N, Fan SL. Single UK centre experience on the treatment of PD peritonitis-antibiotic levels and outcomes. Nephrol Dial Transplant 2007; 22:1714-9.

305. Bennett-Jones D, Wass V, Mawson P. A comparison of intraperitoneal and intravenous/oral antibiotics in CAPD peritonitis. Perit Dial Int 1987; 7:31-3.

306. Boyce NW, Wood C, Thomson NM, Kerr P, Atkins RC. Intraperitoneal (IP) vancomycin therapy for CAPD peritonitis-a prospective, randomized comparison of intermittent v continuous therapy. Am J Kidney Dis 1988; 12:304-6.

307. Low CL, Bailie GR, Evans A, Eisele G, Venezia RA. Pharmacokinetics of once-daily IP gentamicin in CAPD patients. Perit Dial Int 1996; 16:379-84.

308. Low CL, Gopalakrishna K, Lye WC. Pharmacokinetics of once daily intraperitoneal cefazolin in continuous ambulatory peritoneal dialysis patients. J Am Soc Nephrol 2000; 11:1117-21.

309. Manley HJ, Bailie GR, Frye RF, McGoldrick MD. Intravenous vancomycin pharmacokinetics in automated peritoneal dialysis patients. Perit Dial Int 2001; 21:378-85.

310. Manley HJ, Bailie GR, Frye R, McGoldrick MD. Intermittent intravenous piperacillin pharmacokinetics in automated peritoneal dialysis patients. Perit Dial Int 2000; 20:686-93.

311. Schaefer F, Klaus G, Muller-Wiefel DE, Mehls 0 . Intermittent versus continuous intraperitoneal glycopeptide/ceftazidime treatment in children with peritoneal dialysis-associated peritonitis. The Mid-European Pediatric Peritoneal Dialysis Study Group (MEPPS). J Am Soc Nephrol 1999; 10:136-45.

312. Stevenson S, Tang W, Cho Y, Mudge DW, Hawley CM, Badve SV, Johnson DW. The role of monitoring vancomycin levels in patients with peritoneal dialysis-associated peritonitis. Perit Dial Int 2015; 35:222-8.

313. Mulhern JG, Braden GL, O'Shea MH, Madden RL, Lipkowitz GS, Germain MJ. Trough serum vancomycin levels predict the relapse of Grampositive peritonitis in peritoneal dialysis patients. Am J Kidney Dis 1995; 25:611-5.

314. Johnson DW. Do antibiotic levels need to be followed in treating peritoneal dialysis-associated peritonitis? Semin Dial 2011; 24:445-6.

315. Varghese JM, Roberts JA, Wallis SC, Boots RJ, Healy H, Fassett RG, et al. Pharmacokinetics of intraperitoneal gentamicin in peritoneal dialysis patients with peritonitis (GIPD study). Clin J Am Soc Nephrol 2012; $7: 1249-56$

316. Lye WC, van der Straaten JC, Leong S0, Sivaraman P, Tan SH, Tan CC, et al. Once-daily intraperitoneal gentamicin is effective therapy for Gramnegative CAPD peritonitis. Perit Dial Int 1999; 19:357-60.

317. Tang W, Cho Y, Hawley CM, Badve SV, Johnson DW. The role of monitoring gentamicin levels in patients with Gram-negative peritoneal dialysisassociated peritonitis. Perit Dial Int 2014; 34:219-26.

318. Gendeh BS, Said H, Gibb AG, Aziz NS, Zahir ZM. Gentamicin administration via peritoneal dialysis fluid: the risk of ototoxicity. J Laryngol Otol 1991; 105:999-1001.

319. van der Hulst RJ, Boeschoten EW, Nielsen FW, Struijk DG, Dreschler WD, Tange RA. Ototoxicity monitoring with ultra-high frequency audiometry in peritoneal dialysis patients treated with vancomycin or gentamicin. ORL J Otorhinolaryngol Relat Spec 1991; 53:19-22.

320. Nikolaidis P, Vas S, Lawson V, Kennedy-Vosu L, Bernard A, Abraham G, et al. Is intraperitoneal tobramycin ototoxic in CAPD patients? Perit Dial Int 1991; 11:156-61.

321. Gendeh BS, Said H, Gibb AG, Aziz NS, Kong N, Zahir ZM. Gentamicin ototoxicity in continuous ambulatory peritoneal dialysis. J Laryngol

This single copy is for your personal, non-commercial use only.

For permission to reprint multiple copies or to order presentation-ready

copies for distribution, contact Multimed Inc. at marketing@multi-med.com 
Otol 1993; 107:681-5.

322. Cardone KE, Grabe DW, Zasowski EJ, Lodise TP. Reevaluation of ceftazidime dosing recommendations in patients on continuous ambulatory peritoneal dialysis. Antimicrob Agents Chemother 2014; 58:19-26.

323. Yeung SM, Walker SE, Tailor SA, Awdishu L, Tobe S, Yassa T. Pharmacokinetics of oral ciprofloxacin in continuous cycling peritoneal dialysis. Perit Dial Int 2004; 24:447-53.

324. Kays MB, Overholser BR, Mueller BA, Moe SM, Sowinski KM. Effects of sevelamer hydrochloride and calcium acetate on the oral bioavailability of ciprofloxacin. Am J Kidney Dis 2003; 42:1253-9.

325. How PP, Fischer JH, Arruda JA, Lau AH. Effects of lanthanum carbonate on the absorption and oral bioavailability of ciprofloxacin. Clin J Am Soc Nephrol 2007; 2:1235-40.

326. de Vin F, Rutherford P, Faict D. Intraperitoneal administration of drugs in peritoneal dialysis patients: a review of compatibility and guidance for clinical use. Perit Dial Int 2009; 29:5-15.

327. Dooley DP, Tyler JR, Wortham WG, Harrison LS, Starnes WF Jr, Collins GR, et al. Prolonged stability of antimicrobial activity in peritoneal dialysis solutions. Perit Dial Int 2003; 23:58-62.

328. Williamson JC, Volles DF, Lynch PL, Rogers PD, Haverstick DM. Stability of cefepime in peritoneal dialysis solution. Ann Pharmacother 1999; 33:906-9.

329. Tobudic S, Poeppl W, Kratzer C, Vychytil A, Burgmann H. Comparative in vitro antimicrobial activity of vancomycin, teicoplanin, daptomycin and ceftobiprole in four different peritoneal dialysis fluids. Eur J Clin Microbiol Infect Dis 2012; 31:1327-34.

330. Roberts DM, Fernando G, Singer RF, Kennedy KJ, Lawrence M, Talaulikar G. Antibiotic stability in commercial peritoneal dialysis solutions: influence of formulation, storage and duration. Nephrol Dial Transplant 2011; 26:3344-9.

331. Kussmann M, Schuster L, Zeitlinger M, Pichler P, Reznicek G, Wiesholzer $M$, et al. The influence of different peritoneal dialysis fluids on the in vitro activity of ampicillin, daptomycin, and linezolid against Enterococcus faecalis. Eur J Clin Microbiol Infect Dis 2015; 34:2257-63.

332. Robiyanto R, Zaidi ST, Shastri MD, Castelino RL, Wanandy T, Jose MD, et al. Stability of tigecycline in different types of peritoneal dialysis solutions. Perit Dial Int 2016; 36(4):410-14.

333. Voges M, Faict D, Lechien G, Taminne M. Stability of drug additives in peritoneal dialysis solutions in a new container. Perit Dial Int 2004; 24:590-5.

334. Ranganathan D, Naicker S, Wallis SC, Lipman J, Ratnajee SK, Roberts JA. Stability of antibiotics for intraperitoneal administration in extraneal $7.5 \%$ icodextrin peritoneal dialysis bags (STAB Study). Perit Dial Int 2016; 36(4):421-26.

335. de Moraes TP, Olandoski M, Caramori JC, Martin LC, Fernandes N, DivinoFilho JC, et al. Novel predictors of peritonitis-related outcomes in the BRAZPD cohort. Perit Dial Int 2014; 34:179-87.

336. Ejlersen E, Brandi L, Lokkegaard H, Ladefoged J, Kopp R, Haarh P. Is initial (24 hours) lavage necessary in treatment of CAPD peritonitis? Perit Dial Int 1991; 11:38-42.

337. Demoulin N, Goffin E. Intraperitoneal urokinase and oral rifampicin for persisting asymptomatic dialysate infection following acute coagulasenegative Staphylococcus peritonitis. Perit Dial Int 2009; 29:548-53.

338. Tong MK, Leung KT, Siu YP, Lee KF, Lee HK, Yung CY, et al. Use of intraperitoneal urokinase for resistant bacterial peritonitis in continuous ambulatory peritoneal dialysis. J Nephrol 2005; 18:204-8.

339. Gadallah MF, Tamayo A, Sandborn M, Ramdeen G, Moles K. Role of intraperitoneal urokinase in acute peritonitis and prevention of catheter loss in peritoneal dialysis patients. Adv Perit Dial 2000; 16:233-6.

340. Innes A, Burden RP, Finch RG, Morgan AG. Treatment of resistant peritonitis in continuous ambulatory peritoneal dialysis with intraperitoneal urokinase: a double-blind clinical trial. Nephrol Dial Transplant 1994; 9:797-9.

341. Williams AJ, Boletis I, Johnson BF, Raftery AT, Cohen GL, Moorhead PJ, et al. Tenckhoff catheter replacement or intraperitoneal urokinase: a randomised trial in the management of recurrent continuous ambulatory peritoneal dialysis (CAPD) peritonitis. Perit Dial Int 1989; 9:65-7.

342. Chow KM, Szeto CC, Kwan BC, Pang WF, Ma T, Leung CB, et al. Randomized controlled study of icodextrin on the treatment of peritoneal dialysis patients during acute peritonitis. Nephrol Dial Transplant 2014; 29:1438-43.

343. Chow KM, Szeto CC, Cheung KK, Leung CB, Wong SS, Law MC, et al. Predictive value of dialysate cell counts in peritonitis complicating peritoneal dialysis. Clin J Am Soc Nephrol 2006; 1:768-73.

344. Choi P, Nemati E, Banerjee A, Preston E, Levy J, Brown E. Peritoneal dialysis catheter removal for acute peritonitis: a retrospective analysis of factors associated with catheter removal and prolonged postoperative hospitalization. Am J Kidney Dis 2004; 43:103-11.

345. Burke M, Hawley CM, Badve SV, McDonald SP, Brown FG, Boudville N, et al. Relapsing and recurrent peritoneal dialysis-associated peritonitis: a multicenter registry study. Am J Kidney Dis 2011; 58:429-36.

346. Szeto CC, Kwan BC, Chow KM, Law MC, Pang WF, Leung CB, et al. Repeat peritonitis in peritoneal dialysis: retrospective review of 181 consecutive cases. Clin J Am Soc Nephrol 2011; 6:827-33.

347. Thirugnanasambathan T, Hawley CM, Badve SV, McDonald SP, Brown FG, Boudville $\mathrm{N}$, et al. Repeated peritoneal dialysis-associated peritonitis: a multicenter registry study. Am J Kidney Dis 2012; 59:84-91.

348. Lane JC, Warady BA, Feneberg R, Majkowski NL, Watson AR, Fischbach M, et al. Relapsing peritonitis in children who undergo chronic peritoneal dialysis: a prospective study of the international pediatric peritonitis registry. Clin J Am Soc Nephrol 2010; 5:1041-46.

349. Szeto CC, Lai KB, Kwan BC, Chow KM, Leung CB, Law MC, et al. Bacteriaderived DNA fragment in peritoneal dialysis effluent as a predictor of relapsing peritonitis. Clin J Am Soc Nephrol 2013; 8:1935-41.

350. Fan S, Lane C, Punzalan S. Correlation of periscreen strip results and white cell count in peritoneal dialysis peritonitis. J Ren Care 2010; 36:90-5.

351. Szeto CC, Kwan BC, Chow KM, Lau MF, Law MC, Chung KY, et al. Coagulase negative staphylococcal peritonitis in peritoneal dialysis patients: review of 232 consecutive cases. Clin J Am Soc Nephrol 2008; 3:91-7.

352. Camargo CH, Cunha Mde L, Caramori JC, Mondelli AL, Montelli AC, Barretti P. Peritoneal dialysis-related peritonitis due to coagulase-negative Staphylococcus: a review of 115 cases in a Brazilian center. Clin J Am Soc Nephrol 2014; 9:1074-81.

353. Fahim M, Hawley CM, McDonald SP, Brown FG, Rosman JB, Wiggins $\mathrm{KJ}$, et al. Coagulase-negative staphylococcal peritonitis in Australian peritoneal dialysis patients: predictors, treatment and outcomes in 936 cases. Nephrol Dial Transplant 2010; 25:3386-92.

354. Heywood A, Bargman JM. Coagulase-negative staphylococcal peritonitis: outcomes of cephalosporin-resistant strains. Adv Perit Dial 2010; 26:34-6.

355. Kitterer D, Latus J, Pöhlmann C, Alscher MD, Kimmel M. Microbiological surveillance of peritoneal dialysis associated peritonitis: antimicrobial susceptibility profiles of a referral center in Germany over 32 years. PLOS ONE 2015; 10:e135969.

356. Edey M, Hawley CM, McDonald SP, Brown FG, Rosman JB, Wiggins KJ, et al. Enterococcal peritonitis in Australian peritoneal dialysis patients: predictors, treatment and outcomes in 116 cases. Nephrol Dial Transplant 2010; 25:1272-8.

357. Yip T, Tse KC, Ng F, Hung I, Lam MF, Tang S, et al. Clinical course and outcomes of single-organism Enterococcus peritonitis in peritoneal dialysis patients. Perit Dial Int 2011; 31:522-8.

358. Pérez-Fontán M, Rodríguez-Carmona A, Rodríguez-Mayo M. Enterococcal peritonitis in peritoneal dialysis patients: last name matters. Perit Dial Int 2011; 31:513-7.

359. Sutherland SM1, Alexander SR, Feneberg R, Schaefer F, Warady BA. Enterococcal peritonitis in children receiving chronic peritoneal dialysis. Nephrol Dial Transplant 2010; 25: 4048-54.

360. Arias CA, Murray BE. Emergence and management of drug-resistant enterococcal infections. Expert Rev Anti Infect Ther 2008; 6:637-55.

361. Troidle L, Kliger AS, Gorban-Brennan N, Fikrig M, Golden M, Finkelstein F0. Nine episodes of CPD-associated peritonitis with vancomycin resistant enterococci. Kidney Int 1996; 50:1368-72.

362. Unal A, Agkus C, Kocyigit I, Oymak 0, Utas C. Peritoneal dialysis-related peritonitis caused by vancomycin-resistant Enterococcus faecium. Ther Apher Dial 2011; 15:115-6.

This single copy is for your personal, non-commercial use only.

For permission to reprint multiple copies or to order presentation-ready

copies for distribution, contact Multimed Inc. at marketing@multi-med.com 
363. Gilmore JF1, Kim M, LaSalvia MT, Mahoney MV. Treatment of enterococcal peritonitis with intraperitoneal daptomycin in a vancomycin-allergic patient and a review of the literature. Perit Dial Int 2013; 33:353-7.

364. Khadzhynov D, Joukhadar C, Peters H. Plasma and peritoneal dialysate levels during daptomycin therapy for peritonitis. Am J Kidney Dis 2009; 53:911-2.

365. Bahte SK, Bertram A, Burkhardt 0, Martens-Lobenhoffer J, Goedecke V, Bode-Böger SM, et al. Therapeutic serum concentrations of daptomycin after intraperitoneal administration in a patient with peritoneal dialysisassociated peritonitis. J Antimicrob Chemother 2010; 65:1312-4.

366. Yap DY, To KK, Yip TP, Lui SL, Chan TM, Lai KN, et al. Streptococcus bovis peritonitis complicating peritoneal dialysis-a review of 10 years' experience. Perit Dial Int 2012; 32:55-9.

367. O'Shea S, Hawley CM, McDonald SP, Brown FG, Rosman JB, Wiggins KJ, et al. Streptococcal peritonitis in Australian peritoneal dialysis patients: predictors, treatment and outcomes in 287 cases. BMC Nephrol 2009; 10:19.

368. Chao CT, Lee SY, Yang WS, Chen HW, Fang CC, Yen CJ, et al. Viridans streptococci in peritoneal dialysis peritonitis: clinical courses and long-term outcomes. Perit Dial Int 2015; 35:333-41.

369. Szeto CC, Chow KM, Kwan BC, Law MC, Chung KY, Yu S, et al. Staphylococcus aureus peritonitis complicates peritoneal dialysis: review of 245 consecutive cases. Clin J Am Soc Nephrol 2007; 2:245-51.

370. Govindarajulu S, Hawley CM, McDonald SP, Brown FG, Rosman JB, Wiggins $\mathrm{KJ}$, et al. Staphylococcus aureus peritonitis in Australian peritoneal dialysis patients: predictors, treatment and outcomes in 503 cases. Perit Dial Int 2010; 30:311-9.

371. Lin SY, Ho MW, Liu JH, Liu YL, Yeh HC, Hsieh TL, et al. Successful salvage of peritoneal catheter in unresolved methicillin-resistant staphylococcus aureus peritonitis by combination treatment with daptomycin and rifampin. Blood Purif 2011; 32:249-52.

372. Barretti P, Moraes TM, Camargo CH, Caramori JC, Mondelli AL, Montelli AC, et al. Peritoneal dialysis-related peritonitis due to Staphylococcus aureus: a single-center experience over 15 years. PLOS ONE 2012; 7:e31780.

373. Barraclough K, Hawley CM, McDonald SP, Brown FG, Rosman JB, Wiggins $\mathrm{KJ}$, et al. Corynebacterium peritonitis in Australian peritoneal dialysis patients: predictors, treatment and outcomes in 82 cases. Nephrol Dial Transplant 2009; 24:3834-9.

374. Szeto CC, Chow KM, Chung KY, Kwan BC, Leung CB, Li PK. The clinical course of peritoneal dialysis-related peritonitis caused by Corynebacterium species. Nephrol Dial Transplant 2005; 20:2793-6.

375. Bernardini J, Piraino B, Sorkin M. Analysis of continuous ambulatory peritoneal dialysis-related Pseudomonas aeruginosa infections. Am J Med 1987; 83:829-32.

376. Szeto CC, Chow KM, Leung CB, Wong TY, Wu AK, Wang AY, et al. Clinical course of peritonitis due to Pseudomonas species complicating peritoneal dialysis: a review of 104 cases. Kidney Int 2001; 59:2309-15.

377. Siva B, Hawley CM, McDonald SP, Brown FG, Rosman JB, Wiggins KJ, et al. Pseudomonas peritonitis in Australia: predictors, treatment, and outcomes in 191 cases. Clin J Am Soc Nephrol 2009; 4:957-64.

378. Sepandj F, Ceri H, Gibb A, Read R, Olson M. Minimum inhibitory concentration (MIC) versus minimum biofilm eliminating concentration (MBEC) in evaluation of antibiotic sensitivity of gram-negative bacilli causing peritonitis. Perit Dial Int 2004; 24:65-7.

379. Jarvis EM, Hawley CM, McDonald SP, Brown FG, Rosman JB, Wiggins KJ, et al. Predictors, treatment, and outcomes of non-Pseudomonas gramnegative peritonitis. Kidney Int 2010; 78:408-14.

380. Valdes-Sotomayor J, Cirugeda A, Bajo MA, del Peso G, Escudero E, Sánchez-Tomero JA, et al. Increased severity of Escherichia coli peritonitis in peritoneal dialysis patients independent of changes in in vitroantimicrobial susceptibility testing. Perit Dial Int 2003; 23:450-5.

381. Prasad N, Gupta A, Sharma RK, Prasad KN, Gulati S, Sharma AP. Outcome of gram-positive and gram-negative peritonitis in patients on continuous ambulatory peritoneal dialysis: a single center experience. Perit Dial Int 2003; 23(Suppl 2):S144-7.

382. Szeto CC, Chow VC, Chow KM, Lai RW, Chung KY, Leung CB, et al. Enterobacteriaceae peritonitis complicating peritoneal dialysis: a review of 210 consecutive cases. Kidney Int 2006; 69:1245-52.
383. Zurowska A, Feneberg R, Warady BA, Zimmering M, Monteverde M, Testa $\mathrm{S}$, et al. Gram-negative peritonitis in children undergoing long-term peritoneal dialysis. Am J Kidney Dis 2008; 51:455-62.

384. Lin WH, Tseng CC, Wu AB, Yang DC, Cheng SW, Wang MC, et al. Clinical and microbiological characteristics of peritoneal dialysis-related peritonitis caused by Klebsiella pneumoniae in southern Taiwan. J Microbiol Immunol Infect 2015; 48:276-83.

385. Wong SS, Ho PL, Yuen KY. Evolution of antibiotic resistance mechanisms and their relevance to dialysis-related infections. Perit Dial Int 2007; 27(Suppl 2):S272-80.

386. Feng X, Yang X, Yi C, Guo Q, Mao H, Jiang Z, et al. Escherichia coli peritonitis in peritoneal dialysis: the prevalence, antibiotic resistance and clinical outcomes in a South China dialysis center. Perit Dial Int 2014; 34:308-16.

387. Zhang W, Wu YG, Qi XM, Dai H, Lu W, Zhao M. Peritoneal dialysis-related peritonitis with Acinetobacter baumannii: a review of seven cases. Perit Dial Int 2014; 34:317-21.

388. Szeto CC, Li PK, Leung CB, Yu AW, Lui SF, Lai KN. Xanthomonas maltophilia peritonitis in uremic patients receiving continuous ambulatory peritoneal dialysis. Am J Kidney Dis 1997; 29:91-5.

389. Tzanetou K, Triantaphillis G, Tsoutsos D, Petropoulou D, Ganteris G, Malamou-Lada E, et al. Stenotrophomonas maltophilia peritonitis in CAPD patients: susceptibility of antibiotics and treatment outcome: a report of five cases. Perit Dial Int 2004; 24:401-4.

390. Harwell CM, Newman LN, Cacho CP, Mulligan DC, SchulakJA, Friedlander MA. Abdominal catastrophe: visceral injury as a cause of peritonitis in patients treated by peritoneal dialysis. Perit Dial Int 1997; 17:586-94.

391. Faber MD, Yee J. Diagnosis and management of enteric disease and abdominal catastrophe in peritoneal dialysis patients with peritonitis. Adv Chronic Kidney Dis 2006; 13:271-9.

392. Szeto CC, Chow KM, Wong TY, Leung CB, Li PK. Conservative management of polymicrobial peritonitis complicating peritoneal dialysis-a series of 140 consecutive cases. Am J Med 2002; 113:728-33.

393. Barraclough K, Hawley CM, McDonald SP, Brown FG, Rosman JB, Wiggins $\mathrm{KJ}$, et al. Polymicrobial peritonitis in peritoneal dialysis patients in Australia: predictors, treatment, and outcomes. Am J Kidney Dis 2010; 55:121-31.

394. Bunke M, Brier ME, Golper TA. Culture-negative CAPD peritonitis: the Network 9 Study. Adv Perit Dial 1994; 10:174-8.

395. Fahim M, Hawley CM, McDonald SP, Brown FG, Rosman JB, Wiggins KJ, et al. Culture-negative peritonitis in peritoneal dialysis patients in Australia: predictors, treatment and outcomes in 435 cases. Am J Kidney Dis 2010; 55:690-7.

396. Szeto CC, Wong TY, Chow KM, Leung CB, Li PK. The clinical course of culture-negative peritonitis complicating peritoneal dialysis. Am J Kidney Dis 2003; 42:567-74.

397. Miles R, Hawley CM, McDonald SP, Brown FG, Rosman JB, Wiggins KJ, et al. Predictors and outcomes of fungal peritonitis in peritoneal dialysis patients. Kidney Int 2009; 76:622-8.

398. Matuszkiewicz-Rowinska J. Update on fungal peritonitis and its treatment. Perit Dial Int 2009; 29(Suppl 2):S161-5.

399. Nadeau-Fredette AC, Bargman JM. Characteristics and outcomes of fungal peritonitis in a modern North American cohort. Perit Dial Int 2015; 35:78-84.

400. Basturk T, Koc Y, Unsal A, Ahbap E, Sakaci T, Yildiz I, et al. Fungal peritonitis in peritoneal dialysis: a 10-year retrospective analysis in a single center. Eur Rev Med Pharmacol Sci 2012; 16:1696-1700.

401. Cervelli MJ. The Renal Drug Reference Guide. Adelaide: Kidney Health Australia; 2007.

402. Andes D, Pascual A, Marchetti 0. Antifungal therapeutic drug monitoring: established and emerging indications. Antimicrob Agents Chemother $2009 ; 53: 24-34$

403. Levallois J, Nadeau-Fredette AC, Labbé AC, Laverdière M, Ouimet D, Vallée M. Ten-year experience with fungal peritonitis in peritoneal dialysis patients: antifungal susceptibility patterns in a North-American center. Int J Infect Dis 2012; 16:e41-3.

404. Chang TI, Kim HW, Park JT, Lee DH, Lee JH, Yoo TH, et al. Early catheter removal improves patient survival in peritoneal dialysis patients with

This single copy is for your personal, non-commercial use only.

For permission to reprint multiple copies or to order presentation-ready

copies for distribution, contact Multimed Inc. at marketing@multi-med.com 
fungal peritonitis: results of ninety-four episodes of fungal peritonitis at a single center. Perit Dial Int 2011; 31:60-6.

405. Lye WC. Rapid diagnosis of Mycobacterium tuberculous peritonitis in two continuous ambulatory peritoneal dialysis patients, using DNA amplification by polymerase chain reaction. Adv Perit Dial 2002; 18:154-7.

406. Chow KM, Chow VC, Hung LC, Wong SM, Szeto CC. Tuberculous peritonitisassociated mortality is high among patients waiting for the results of mycobacterial cultures of ascitic fluid samples. Clin Infect Dis 2002; 35:409-13.

407. Ahn C, Oh KH, Kim K, Lee KY, Lee JG, Oh MD, et al. Effect of peritoneal dialysis on plasma and peritoneal fluid concentrations of isoniazid, pyrazinamide, and rifampin. Perit Dial Int 2003; 23:362-7.

408. Abraham G, Mathews M, Sekar L, Srikanth A, Sekar U, Soundarajan P. Tuberculous peritonitis in a cohort of continuous ambulatory peritoneal dialysis patients. Perit Dial Int 2001; 21(Suppl 3):S202-4.

409. Gupta N, Prakash KC. Asymptomatic tuberculous peritonitis in a CAPD patient. Perit Dial Int 2001; 21:416-7.

410. Lui SL, Tang S, Li FK, Choy BY, Chan TM, Lo WK, et al. Tuberculosis infection in Chinese patients undergoing continuous ambulatory peritoneal dialysis. Am J Kidney Dis 2001; 38:1055-60.

411. Lui SL, Lo CY, Choy BY, Chan TM, Lo WK, Cheng IK. Optimal treatment and long-term outcome of tuberculous peritonitis complicating continuous ambulatory peritoneal dialysis. Am J Kidney Dis 1996; 28:747-51.

412. Ogutmen B, Tuglular S, Al Ahdab H, Akoglu E, Ozener Q. Tuberculosis peritonitis with clear fluid accompanying systemic disseminated tuberculosis in a CAPD patient. Perit Dial Int 2003; 23:95-6.

413. Akpolat T. Tuberculous peritonitis. Perit Dial Int 2009; 29(Suppl 2):S166-9.

414. Bhowmik D, Mahajan S, Bora M. Concerns regarding the ISPD guidelines / recommendations for peritonitis due to mycobacteria. Perit Dial Int 2011; 31:363-4.

415. Ram R, Swarnalatha G, Akpolat T, Dakshinamurty KV. Mycobacterium tuberculous peritonitis in CAPD patients: a report of 11 patients and review of literature. Int Urol Nephrol 2013; 45:1129-35.

416. Harro C, Braden GL, Morris AB, Lipkowitz GS, Madden RL. Failure to cure Mycobacterium gordonae peritonitis associated with continuous ambulatory peritoneal dialysis. Clin Infect Dis 1997; 24:955-7.

417. White R, Abreo K, Flanagan R, Gadallah M, Krane K, el-Shahawy M, et al. Nontuberculous mycobacterial infections in continuous ambulatory peritoneal dialysis patients. Am J Kidney Dis 1993; 22:581-7.
418. Tse KC, Lui SL, Cheng VC, Yip TP, Lo WK. A cluster of rapidly growing mycobacterial peritoneal dialysis catheter exit-site infections. Am J Kidney Dis 2007; 50:e1-5.

419. Jiang SH, Roberts DM, Dawson AH, Jardine M. Mycobacterium fortuitum as a cause of peritoneal dialysis-associated peritonitis: case report and review of the literature. BMC Nephrol 2012; 13:35.

420. Song Y, Wu J, Yan H, Chen J. Peritoneal dialysis-associated nontuberculous mycobacterium peritonitis: a systematic review of reported cases. Nephrol Dial Transplant 2012; 27:1639-44.

421. Renaud CJ, Subramanian S, Tambyah PA, Lee EJ. The clinical course of rapidly growing nontuberculous mycobacterial peritoneal dialysis infections in Asians: a case series and literature review. Nephrology (Carlton) 2011; 16:174-9.

422. Jiang SH, Roberts DM, Clayton PA, Jardine M. Non-tuberculous mycobacterial PD peritonitis in Australia. Int Urol Nephrol 2013; 45:1423-8.

423. Szeto CC, Chow KM, Wong TY, Leung CB, Wang AY, Lui SF, et al. Feasibility of resuming peritoneal dialysis after severe peritonitis and Tenckhoff catheter removal. J Am Soc Nephrol 2002; 13:1040-5.

424. Troidle L, Gorban-Brennan N, Finkelstein F0. Outcome of patients on chronic peritoneal dialysis undergoing peritoneal catheter removal because of peritonitis. Adv Perit Dial 2005; 21:98-101.

425. Ram R, Swarnalatha G, Dakshinamurty KV. Reinitiation of peritoneal dialysis after catheter removal for refractory peritonitis. J Nephrol 2014; 27:445-9.

426. Cho Y, Badve SV, Hawley CM, McDonald SP, Brown FG, Boudville N, et al. Peritoneal dialysis outcomes after temporary haemodialysis transfer for peritonitis. Nephrol Dial Transplant 2014; 29:1940-7.

427. Szeto CC, Kwan BC, Chow KM, Pang WF, Kwong VW, Leung CB, et al. Persistent symptomatic intra-abdominal collection after catheter removal for PD-related peritonitis. Perit Dial Int 2011; 31:34-8.

428. Ranganathan D, Varghese JM, Fassett RG, Lipman J, D'Intini V, Healy H, et al. Optimising intraperitoneal gentamicin dosing in peritoneal dialysis patients with peritonitis (GIPD) study. BMC Nephrol 2009; 10:42.

(c) (i) $\odot$ This work is licensed under the Creative Commons Attribution-NonCommercial-NoDerivatives $\mathbf{4 . 0}$ International License. To view a copy of this license, visit http:// creativecommons.org/licenses/by-nc-nd/4.0/. For commercial re-use, please contact marketing@multi-med.com

This single copy is for your personal, non-commercial use only. For permission to reprint multiple copies or to order presentation-ready copies for distribution, contact Multimed Inc. at marketing@multi-med.com 